\title{
Montesquieus Lettres persanes oder der Blick der Anderen auf das Eigene
}

Die Frage des Raums und der damit verbundenen Konvivenz steht zweifellos im Zentrum eines Werks, das sich bis zum heutigen Tage immer neuer Ausgaben und Editionen erfreut: die Lettres persanes von Montesquieu. Bevor wir uns aber mit diesem Schlüsselwerk der französischen und europäischen Aufklärung beschäftigen können, müssen wir zunächst noch in der gebotenen Kürze eine Reihe zentraler Fragen klären: Hat sich im 18. Jahrhundert lediglich die Dimension des Raumes verändert? Wie steht es mit der Dimension der Zeit? Wie also verhält sich das 18. Jahrhundert gegenüber unterschiedlichen Vorstellungen von Zeit, und lassen sich zwischen diesen signifikante Veränderungen erkennen? Gibt es ein Charakteristikum, das das Jahrhundert der Aufklärung gegenüber anderen, früheren Jahrhunderten im Sinne eines veränderten Zeitbewusstseins auszeichnet?

Die Antwort auf diese Fragen ist klar: Ja, es lässt sich ein verändertes Zeitbewusstsein im Jahrhundert der Aufklärung beobachten. Und zwar nicht erst im Kontext der Französischen Revolution, wo sich mittlerweile unbestritten ein progressives, zukunftsoffenes und vom Menschen zu gestaltendes Bewusstsein der Zeit jenseits zyklischer Zeitvorstellungen herausbildete. Wir werden auf diese grundlegenden Veränderungen, die ich ebenfalls in meiner Vorlesung über Romantik zwischen zwei Welten dargestellt habe, in unserer aktuellen Vorlesung aus anderem Blickwinkel zurückkommen, sobald wir im letzten Drittel des 18. Jahrhunderts angekommen sein werden.

Signifikante Veränderungen lassen sich bereits einhundert Jahre vor der Französischen Revolution erkennen. Werfen wir also einen Blick auf die achtziger Jahre des 17. Jahrhunderts, um genauer zu sein: auf den Januar des Jahres 1687! Man könnte formulieren, dass sich in jenem denkwürdigen Januar die Dinge in Bewegung setzten. Denn er markiert den eigentlichen Beginn des Siècle des Lumières. Es handelt sich dabei - vielleicht haben Sie schon davon gehört - um die sogenannte Querelle des Anciens et des Modernes, um die Auseinandersetzung zwischen den Alten und den Modernen, deren Verlauf ich Ihnen in aller Kürze vorstellen möchte.

Bei diesem Streit zwischen den Vertretern der Antike und denen, die sich als die „Modernen“ bezeichneten, ging es zunächst und im Grunde um eine veränderte Beurteilung der griechisch-römischen Antike. Es handelte sich letztlich um eine Auflehnung gegen die fortbestehende Musterhaftigkeit der Antike, so wie sie - zumindest in der Sichtweise des 17. Jahrhunderts - für die französische Klassik gegolten hatte. Der Freiburger Romanist Erich Köhler hat - in Anlehnung an den großen 
Werner Krauss ${ }^{1}$ - freilich verdeutlicht, dass diese Auseinandersetzung letztlich nicht mehr und nicht weniger als ein neues Geschichtsbewusstsein der Epoche betraf.

Der Secrétaire perpétuel der Académie Française, Fontenelle, der sich schon zuvor von der Antike als alleinigem Leitmuster distanziert hatte, griff in die Querelle des Anciens et des Modernes ein; der Wortführer der „Modernes“ aber war Charles Perrault. Zu ihren Parteigängern gehörten des weiteren Saint-Evremond, Pierre Bayle sowie Thomas Corneille, um Ihnen einige der profiliertesten Vertreter der Zeit zu nennen. Zu den Verteidigern der „Anciens“ wiederum zählten Racine, Boileau, La Fontaine, die Jansenisten um Port-Royal und viele andere der weitbekannten Vertreter der französischen Klassik, so dass wir es bei dieser Querelle folglich mit einem Aufeinandertreffen der bekanntesten Autoren und Philosophen der Zeit in Frankreich zu tun haben.

Der Streit brach nach einigen Vorgefechten während einer Sitzung der Académie Française am 27. Januar 1687 los, als Charles Perrault in seinem Gedicht Le siécle de Louis le Grand die folgenden Verse ins Auditorium schleuderte:

Die schöne Antike war stets zu verehren;

Doch glaubte ich nie, sie seien Götter, die hehren.

Ich sehe die Alten, ohne mein Knie zu beugen,

Sie sind groß, doch als Menschen wie wir zu bezeugen;

Und man kann ohne Furcht, man wäre iniustus,

Des Großen Ludwig Zeit vergleichen mit Augustus.

La belle Antiquité fut toujours vénérable;

Mais je ne crus jamais qu'elle fust adorable.

Je voy les Anciens sans plier les genoux,

Ils sont grands, il est vray, mais hommes comme nous;

Et l'on peut comparer sans craindre d'estre injuste,

Le Siècle de Louis au beau Siècle d'Auguste. ${ }^{2}$

Das war verstechnisch versiert in regelmäßige Alexandriner gegossen und wie so oft in Frankreich formvollendet, aber in der Sache kompromisslos hart. Um es mit einem Wort zu sagen: Dieser Angriff traf. Und von nun an ging es Schlag auf Schlag, nachdem man auch noch Platon, den Fürsten der Philosophen, der Langeweile bezichtigt hatte. Erich Köhler schilderte in seinen Vorlesungen zur Frühaufklärung recht hübsch und mit einem schwäbischen Akzent, den ich nicht

1 Vgl. hierzu Ette, Ottmar / Fontius, Martin / Haßler, Gerda / Jehle, Peter (Hg.): Werner Krauss. Wege - Werke - Wirkungen. Berlin: Berlin Verlag 1999.

2 Perrault, Charles: Le siècle de Louis le Grand. Par M. Perrault de l'Académie Françoise. Paris: Chez Jean Baptiste Coignard 1687, S. 3. 
mehr vergessen kann, dass Boileau, seit der ersten Zeile des Gedichts finsteren Angesichts, beim Vortrag auf seinem Sitz hin und her zu rutschen begann. ${ }^{3}$

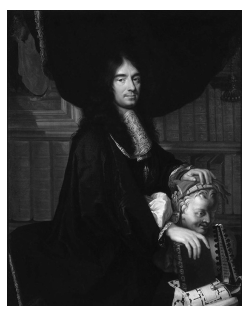

Abb. 14: Philippe Lallemand: Charles Perrault (1628-1703).

Doch Boileau rutschte nicht nur, er tobte und ging alsbald zum Gegenangriff über. Wir sollten uns nicht allzu lange mit den Einzelheiten der sich nun anschließenden Kämpfe und Auseinandersetzungen beschäftigen, die freilich sehr gut die schwierigen Anfangsjahre dessen bezeichnen, was wir als Frühaufklärung verstehen müssen. Perrault reagierte seinerseits auf Boileau und veröffentlichte zwischen 1688 und 1697 seine vierbändigen Parallèles des Anciens et des Modernes, eine Reihe von Dialogen im Sinne von Vergleichen zwischen Anciens und Modernes, in denen die Leistungen der Modernen herausgestrichen wurden. Es ging nicht um wirkliche Vergleiche, sondern um polemisch eingefärbte Dialoge, die stets zugunsten der Modernen ausfielen. Erich Köhler betonte mit guten Gründen, dass dem Hauptmotiv jenes ansonsten nicht weiter wichtigen Werkes die Zukunft gehören sollte. Und dieses war nichts Geringeres als schlicht der Gedanke des historischen Fortschritts.

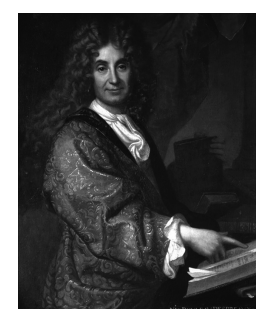

Abb. 15: Jean-Baptiste Santerre: Nicolas Boileau (1636-1711).

Bernard le Bovier de Fontenelle hatte zuvor schon in die laufende Debatte eingegriffen mit der Veröffentlichung seiner Digressions sur les Anciens et les Modernes, wo der Fortschritts-Gedanke in Rückgriff auf Descartes entfaltet wird.

3 Vgl. Köhler, Erich: Frühaufklärung. Herausgegeben von Dietmar Rieger. Stuttgart: Kohlhammer 1983, S. 29. 
Schließlich hatte René Descartes bereits die Größe der Antike relativiert und darauf hingewiesen, dass die Zeitgenossen sehr wohl über eine höhere historische Reichweite verfügten, da sie auf die Erfahrungen ihrer Vorläufer zurückgreifen konnten. Fontenelle zog daraus sozusagen die geschichtsphilosophischen Konsequenzen, indem er die cartesianische Mechanik nun geschichtlich wendete, wie Erich Köhler dies in seiner noch immer lesenswerten Vorlesung über die französische Frühaufklärung formulierte.

Damit war eine generelle Fragestellung wesentlich tangiert. Denn es ging um die allmähliche Beseitigung falscher Vorstellungen und die Zunahme an historisch akkumulierten Erkenntnissen im Laufe der Geschichte. Grundlage für eine derartige Anschauung war die Akkumulation des Wissens oder, wie wir auch sagen könnten, die Aufhäufung vernunftbegründeter Einsichten, welche - um eine mittelalterliche Vorstellung zu benutzen - uns zu Zwergen auf den Schultern von Riesen machen, die freilich trotz ihrer zwergenhaften Gestalt die Höhe der Riesen überragen können. Auch der ,Rückfall“ des Mittelalters in die ,Finsternisse“ einer „Media Aetas“ änderte für Fontenelle nichts am Glauben an den allgemeinen Fortschritt in der menschlichen Geschichte. So wird der Fortschritt für ihn zum wesentlichen und absoluten Prinzip, besonders auch mit Blick auf die Geschichte der Menschheit und des menschlichen Bewusstseins: Der Fortschritt wird zum Motor jeder Art von menschlicher Geschichte. das war nun freilich etwas ganz anderes als jenes Paradigma, das in der Antike prinzipiell das unüberbietbare Vorbild erblickte. sie merken, was in dieser Debatte auf dem Spiele stand.

Wir wissen heute selbstverständlich, welche Seite sich letztlich durchsetzen konnte, selbst wenn noch heutzutage in manchen Fächern der Glaube vorzuherrschen scheint, dass die Leistungen der Antike letztlich niemals zu überbieten seien und dass es auch nichts Neues unter der Sonne gebe. Wir können solcherlei Auffassungen, die sich gerne den Anschein des Humanismus geben, in dessen Dunkelkammer verweisen, scheinen die Vertreterinnen derartiger Meinungen doch noch vor der Akademiesitzung, welche die Querelle des Anciens et des Modernes auslöste, buchstäblich sitzen geblieben zu sein. Einmal ganz abgesehen von der Tatsache, dass wir hier einen fundamentalen Eurozentrismus am Werke sehen. Derartige Anschauungen können wir getrost unter der Rubrik „Folklore“ verbuchen, so wie 23,5 Prozent der US-Amerikaner neuen Umfragen zufolge nicht der Ansicht sind, dass die Erde eine Kugel sei, sondern sich unseren Planeten so flach wie eine Pizza vorstellen - wahrscheinlich nicht einmal wie eine italienische Pizza, sondern eine von Pizza Hut. Doch lassen Sie uns wieder zum Ernst der Diskussionen zurückkehren!

Die Querelle brachte ausgehend von einer Homer-Übersetzung durch Madame Lefèvre-Dadier zugleich eine neue Komponente mit in die Auseinandersetzungen ein, nämlich die Frage, inwieweit die Frauen aktiv in das kulturelle Leben, in die 
Kunst eingreifen dürften. Auch in dieser Frage war die Position von Charles Perrault klar gegen jene der Antikenvertreter gerichtet. Perrault machte dies in seiner Apologie des femmes deutlich. Auch auf diesem Feld also kündigt sich die Abkehr von der normativen Regelästhetik der französischen Klassik, der „Doctrine classique“, an: Eine neue Bewertung, ein neues Paradigma eröffnet sich, das freilich noch keineswegs direkt in die Französische Revolution führt.

Doch werden wir bezüglich dieser sich anbahnenden Entwicklung eine Reihe von zusätzlichen Einsichten benötigen. Jedenfalls schreibt Köhler: „Den modernen gehörte die Zukunft, weil die Zukunft der Fortschrittsidee gehörte. “4 Dem schließe ich mich an, auch wenn sich die beiden Kampfhähne Perrault und Boileau 1694 auf Betreiben Arnaulds unter der „Coupole“ der Académie Française wieder versöhnten: Eine entscheidende Schlacht war geschlagen. Und die Fortschritts-Idee begann, sich nicht nur im französischen Geistesleben zusätzliches Terrain zu erobern. Ihre Vorstellungen sickerten langsam auch weit über die Grenzen Europas hinaus.

So wurde im Bereich des Ästhetischen letztlich eine philosophische Frage verhandelt, nämlich die Gewichtung eines dynamischen und progressiven, auf Kosten eines normativ-statischen Prinzips. Mit anderen Worten: Die Dinge gerieten auch hier in Bewegung. Die Modernen erschienen zumindest auf ästhetischer Ebene zunächst noch wie Bilderstürmer, die sich gegen die Tradition wandten, während die Frühaufklärer diesen Kampf gegen die überkommenen Traditionen auf philosophischem Gebiet ausfochten. Kritik und Literaturkritik waren bei der Befreiung von Vorurteilen kritisch bei der Sache: Kants Betonung ihrer Rolle gilt für das gesamte 18. Jahrhundert.

Wir könnten an dieser Stelle folglich hinzufügen, dass wir nicht nur eine Ausweitung des denkbaren Raumes im kosmopolitischen Denken beobachten können, sondern auch eine Ausweitung auf der zeitlichen Ebene insoweit, als dass nun zunehmend eine vierte Dimension, eine veränderte Dimension der Zeit, in das Denken Einzug hielt und die Idee des Fortschritts in den Köpfen verankerte. Mitentscheidend war die Tatsache, dass dieser Fortschritt zu einem Teil zeitgenössischer Erfahrung, also zu einer Lebenserfahrung wurde, die von einem stetig wachsenden Teil der Bevölkerung im Verlauf des 18. Jahrhunderts geteilt wurde. Damit aber veränderte sich die Sichtweise von Welt und Dasein und letztlich die Konzeption raumzeitlicher Zusammenhänge überhaupt. Dies waren sich langsam herausbildende Einsichten und Grundlagen für die zweite Hälfte des Jahrhunderts der Aufklärung.

4 Köhler, Erich: Frühaufklärung, S. 30. 
Damit aber können wir nun endlich zum in diesem Abschnitt unserer Vorlesung zentral gestellten Text kommen. Sechs Jahre nach dem Tode von Louis XIV, der in Charles Perraults Gedicht noch als „Louis le Grand“ erschien, veröffentlichte ein junger Adliger anonym in einem zwar angegebenen, aber nicht existierenden Verlag zu Köln eine Schrift, welche die Sichtweise nicht existierender Perser auf das zeitgenössische Frankreich bot. Dieser auf den ersten Blick eher marginale Text, der in den ersten Monaten des Jahres 1721 erschien, wurde zu einem enormen Publikumserfolg, so dass nicht nur im selben Jahr weitere Auflagen folgten, sondern auch Adaptionen und „,contrefaçons“ publiziert wurden, wie sie die reichhaltige literarische Tradition des 18. Jahrhunderts so liebte.

Die literarische Erfindung von Persern, die zu Besuch in Europa sind, auf Frankreich blicken und dessen Entwicklung sozusagen von außen betrachten, war keineswegs neu: In ihr bestand keineswegs die Originalität und Attraktivität dieses Textes. Es handelte sich vielmehr um die Wiederaufnahme einer literarischen Tradition, die gerade mit Blick auf den Orientalismus, ${ }^{5}$ die Orientverliebtheit des französischen Denkens des beginnenden 18. Jahrhunderts, eine Reihe von Vorläufern gekannt hatte, welche etwa nicht weniger erflunkerte Chinesen diesen ,fremden' Blick auf die ,eigene‘ Welt der Europäer und Franzosen hatten werfen lassen. Das Verfahren als solches war also nichts Neues, wohl aber die Meisterschaft, mit welcher es dieser junge französische Adelige namens Montesquieu für seine letztlich philosophischen Zwecke nutzte. Ein großer Denker des 18. Jahrhunderts kündigte sich hier an.

Bevor wir uns der Analyse dieses Textes zuwenden, sollten wir uns zunächst und kurz mit der Frage beschäftigen, warum es denn zu diesem literarischen Bauchrednertum kam, das darin bestand, aus europäischer Sicht außereuropäische Figuren zu erfinden, die sich ihrerseits wiederum über Europa beugten. Warum also diese Maskerade, diese Erfindung eines Anderen, den es gar nicht gab?

Wir könnten an dieser Stelle vielleicht darauf verweisen, dass es noch sehr lange - nämlich bis ins 20. Jahrhundert - dauern sollte, bis es tatsächlich einen solchen außereuropäischen Blick auf die europäische Welt gab, der in Europa überhaupt wahrgenommen wurde. Es gab zwar wesentlich frühere Zeugnisse nicht-europäischer Reisender oder Staatsbürger, die sich über Europa ausließen, aber kein breites Publikum, welches sich für derartige Texte begeistern ließ. Etwas anderes war es mit ,Ausländern‘, die von ,Inländern“ erfunden wurden. Denn der Stolz Europas war es ja, sich über andere Weltgebiete auszulassen, Meinungen

5 Vgl. hierzu die grundlegende Studie von Said, Edward W.: Orientalism. New York: Vintage Books 1979. 
und Urteile zu bilden, wobei umgekehrt den ,Anderen` ein Blick auf ,unser` Europa letztlich nicht zugestanden wurde. Ein erster Schritt hierzu war immerhin die Erfindung des Anderen, der freilich mit den Worten des Eigenen, also mit europäischen Überlegungen sowie europäischen Zielvorstellungen spricht und Kritik an aktuellen Zuständen in europäischen Gemeinwesen äußern darf. Wann kam diesbezüglich die Wende hin zu einer Situation, in der sich auch Außereuropa in Europa Gehör verschaffen konnte?

Gestatten Sie mir an dieser Stelle unserer Vorlesung einen kleinen Einschub! Bereits vor geraumer Zeit hat der Saarbrücker Aufklärungsforscher Hans-Jürgen Lüsebrink mehrfach auf die Bedeutung hingewiesen, welche den Diskussionen um einen 1921 - also genau zweihundert Jahre nach dem Erscheinen von Montesquieus Lettres persanes - in Frankreich mit dem renommierten Prix Goncourt ausgezeichneten Roman zukommt. ${ }^{6}$ Sein Verfasser war René Maran, ein auf der Antilleninsel Martinique geborener schwarzer Schriftsteller, der nach seinem Abitur in Frankreich lange Jahre in der französischen Kolonialverwaltung im subsaharischen Afrika arbeitete. Er hatte in seinem Roman Batouala mit dem programmatischen Untertitel véritable roman nègre ,aus der Innensicht afrikanischer Gesellschaften“ den Beginn der militärischen und kulturellen Eroberung jenes Teiles von Afrika dargestellt, den wir unter dem Namen Zentralafrikanische Republik und heute wieder unter jener des Kongo kennen. ${ }^{7}$ Dieser wahrhaft schwarze Roman erregte Aufsehen, blieb aber nicht ohne Widerspruch in der französischen Öffentlichkeit des 20. Jahrhunderts nach dem Ende der „Grande Guerre“, in der viele schwarze Soldaten für die Sache Frankreichs gekämpft hatten.

René Maran erhielt zwar als erster Schriftsteller der außereuropäischen frankophonen Literaturen diesen angesehensten französischen Literaturpreis und avancierte bald schon zum Vorreiter einer neuen, ,schwarzen' afrikanischen Literatur, die dem kolonialen Blick europäischer Autoren jegliche Legitimität bestritt. Doch verlor er nach diesem gewaltigen und letztlich überraschenden Erfolg umgehend seine Stellung innerhalb der Kolonialverwaltung, und sein Buch wurde schleunigst im französischen Kolonialreich verboten. Eine Zensur des Buches in Frankreich selbst konnte nach einer hitzigen Debatte in der französischen Nationalversammlung am 21. Dezember 1922 gerade noch abgewendet werden, wobei auch ein Argument zum Tragen kam, das der französische Abgeordnete René Guillemant wie

\footnotetext{
6 Vgl. u.a. Lüsebrink, Hans-Jürgen: „Batouala, véritable roman nègre“: la place de René Maran dans la littérature mondiale des années vingt. In: Riesz, János / Ricard, Alain: Semper aliquid novi. Littérature Comparée et Littératures d'Afrique. Mélanges offerts à Albert Gérard. Tübingen: Narr 1990, S. 145-155; sowie (ders.): „Identités mosaïques“. Zur interkulturellen Dimension frankophoner Literaturen und Kulturen. In: Grenzgänge (Leipzig) II, 4 (1995), S. 6-22. 7 Ebda., S. 14.
} 
folgt formulierte: „Seit langen Jahrhunderten, seit immer schon sind es die Weißen, die schreiben. Sie schreiben, was sie wollen, über die „Neger“. Jetzt aber, da zum ersten Male ein „Neger“ etwas schreibt, das Ihnen missfällt, verteidigen Sie ihn nicht. “8

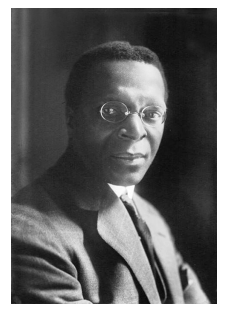

Abb. 16: René Maran (1887-1960), 1923.

Wer hat das Recht, über Afrika zu schreiben? Vielleicht alleine die Weißen? Und wer hat das Recht, ein außereuropäisches wie ein europäisches Publikum mit diesem Schreiben zu erreichen? Die hier aufgeworfene Frage blieb nicht auf den afrikanischen Kontinent beschränkt, sondern traf gerade mit Blick auf Europa ins Schwarze. Denn wenn man mit guten Gründen behaupten kann, dass Europa stets von seinen Rändern her konstruiert wurde, von den Orten seiner Bedrohung her wie auch - allgemeiner - von den Orten einer konkreten Erfahrung radikaler Alterität, so lässt sich zugleich behaupten, dass die Meinungen und Ansichten, die Nicht-Europäer über Europa äußerten, in Europa selbst nie wirklich zu Wort kamen. Wer aber hat ein Recht, über Europa zu sprechen?

Jahrhundertelang war das öffentliche Nachdenken über Europa ein wohlgehütetes Monopol der Europäer. Nur sie durften es sich herausnehmen, Kritik an Europa oder an einzelnen Staaten zu üben. Es waren bestenfalls die europäischen Bauchredner, die seit Hernán Cortés, seit der Unterwerfung Amerikas, die anderen zum Sprechen brachten und über Europa und die dortigen Verhältnisse sich äußern ließen. Dies gilt für Cortés ${ }^{9}$ und ,seinen“ Moctezuma im 16. Jahrhundert, auf den wir noch im Umfeld von Friedrich dem Großen von Preußen zurückkommen werden; dies gilt für Montesquieu mit ,seinen' Lettres persanes im 18. Jahrhundert;

8 Zit. nach ebda., S. 15: „Depuis des siècles, depuis toujours, ce sont les Blancs qui écrivent. Ils écrivent ce qu'ils veulent sur les Nègres. Pour une fois qu'un Nègre a écrit quelque chose qui vous déplaît, vous ne le défendez pas.“

9 Vgl. hierzu Ette, Ottmar: Funktionen von Mythen und Legenden in Texten des 16. und 17. Jahrhunderts über die Neue Welt. In: Kohut, Karl (Hg.): Der eroberte Kontinent. Historische Realität, Rechtfertigung und literarische Darstellung der Kolonisation Amerikas. Frankfurt am Main: Vervuert Verlag 1991, S. 161-182. 
und dies gilt aber auch für Scheurmann und ,seinen“ Tuiavii im Papalagi ${ }^{10}$ im 20. Jahrhundert. ${ }^{11}$ Die Nicht-Europäer selbst aber kommen nur selten zu Wort, genauer: Sie werden in Europa nicht gehört, geschweige denn wirklich wahrgenommen.

Dies gilt im 18. Jahrhundert besonders für jene längst nicht in all ihren Aspekten historisch gewordene Disputa del Nuovo Mondo, die Antonello Gerbi ${ }^{12}$ darstellte und in der die Europäer sich das alleinige Recht anmaßten, über die außereuropäische Welt und insbesondere über Amerika definitive Urteile abzugeben, unabhängig davon, ob sie die ,Neue Welt' aus eigener Erfahrung kannten oder nicht. ${ }^{13}$ Mit einem Teilbereich dieser Disputa, mit der sogenannten Berliner Debatte um die Neue Welt, werden wir uns noch in unserer Vorlesung $\mathrm{zu}$ beschäftigen haben. ${ }^{14}$

Umgekehrt aber blieben die Ohren verschlossen für Autoren wie den mexikanischen Dominikanermönch Fray Servando Teresa de Mier an der Wende des 18. zum 19. Jahrhundert, für den Argentinier Domingo Faustino Sarmiento oder den Chilenen Benjamín Vicuña Mackenna im 19. Jahrhundert wie für viele andere. Dies selbst dann, als sich im 20. Jahrhundert eine Entwicklung anbahnte, in deren Verlauf nun das (ehemalige) Kolonialreich - gemäß der glücklichen Formel The Em-

10 Vgl. Scheurmann, Erich: Der Papalagi. Die Reden des Südseehäuptlings Tuiavii. München: Heyne 1989; die Metamorphose dieses Textes der zwanziger Jahre zu einem Kultbuch der siebziger Jahre bleibt bis heute ein erstaunliches und bemerkenswertes Faktum.

11 Aus diesem Blickwinkel besonders empfehlenswert ist die Lektüre von Barth, Michael u. a. (Hg.): Einmal Eldorado und zurück. Interkulturelle Texte spanischsprachiges Amerika - deutschsprachiges Europa. Koordination Eva-Maria Willkop und Dieter Rall. München: Iudicium Verlag 1992.

12 Vgl. Gerbi, Antonello: La Disputa del Nuovo Mondo. Storia di una polemica 1750-1900. Mailand - Neapel 1955.

13 Vgl. hierzu Ette, Ottmar: Wörter - Mächte - Stämme. Cornelius de Pauw und der Disput um eine neue Welt. In: Messling, Markus / Ette, Ottmar (Hg.): Wort Macht Stamm. Rassismus und Determinismus in der Philologie (18. / 19. Jh.). Unter Mitarbeit von Philipp Krämer und Markus A. Lenz. München: Wilhelm Fink Verlag 2013, S. 107-135; sowie Ette, Ottmar: Circulaciones del saber. Cornelius de Pauw y la Disputa por un Mundo Nuevo. In: Calvo, Luis / Girón, Alvaro / Puig-Samper, Miguel Angel (Hg.): Naturaleza y laboratorio. Barcelona: Residència d'Investigadors CSIC - Generalitat de Catalunya 2016, S. 13-53.

14 Vgl. Von Rousseau und Diderot zu Pernety und de Pauw: Die Berliner Debatte um die Neue Welt. In: Dill, Hans-Otto (Hg.): Jean-Jacques Rousseau zwischen Aufklärung und Moderne. Akten der Rousseau-Konferenz der Leibniz-Sozietät der Wissenschaften zu Berlin am 13. Dezember 2012 anläßlich seines 300. Geburtstages am 28. Juni 2012 im Rathaus Berlin-Mitte. Berlin: Leibniz-Sozietät der Wissenschaften (= Sitzungsberichte der Leibniz-Sozietät der Wissenschaften 117) 2013, S. 111-130; sowie Bernaschina, Vicente / Kraft, Tobias / Kraume, Anne (Hg.): Globalisierung in Zeiten der Aufklärung. Texte und Kontexte zur „Berliner Debatte“ um die Neue Welt (17./18. Jh.). 2 Bde. Frankfurt am Main - Bern - New York: Peter Lang Edition 2015. 
pire writes back ${ }^{15}$ - zurückschrieb und die Vielzahl dieser lauter gewordenen Stimmen auch in Europa nicht länger völlig überhört werden konnte. Der Prix Goncourt für Batouala - véritable roman nègre, der von ihm ausgelöste Skandal und die vehement geführten Polemiken um das Hauptwerk René Marans markieren diesen wichtigen Moment in der Veränderung des postkolonialen Diskurses auf besonders eindrucksvolle und - angesichts der Rezeption in Deutschland, wo der Roman propagandistisch gegen den Kolonialismus des ,Erzfeindes' Frankreich gelesen wurde - zugleich widerspruchsvolle Weise. All dies verweist nochmals eindrücklich auf die Asymmetrie transatlantischer Beziehungen ${ }^{16}$ bis in unsere Gegenwart.

Man sollte die Wirkungen des postkolonialen Diskurses in der sogenannten ,Ersten Welt ${ }^{*}$ gerade aber auch in Europa und speziell in Deutschland - gewiss nicht überschätzen. Auch sind die philologischen Grundlagen vieler „Postcolonial Studies“ oftmals mehr als fragwürdig, eine Tatsache, auf die wir noch an entsprechender Stelle eingehen werden. Der Blick ,der Anderen' ist, gerade wenn er außereuropäisch geprägt ist, noch längst nicht zu einem integralen Bestandteil der Selbstreflexion Europas geworden. Langfristige institutionelle Folgen haben sich daraus auch hierzulande etwa für unser Universitätssystem noch immer nicht ergeben: In einer globalisierten Welt definieren wir unsere innovativen Ansätze noch immer, als ob von Europa alle wichtigen Impulse des kulturellen und gesellschaftlichen Lebens ausgegangen wären und auch weiterhin ausgingen.

Gerade in Deutschland, dessen Wirtschaft sich wie in kaum einem anderen Land der Erde auf globale Strukturen eingestellt hat und weltumspannend verflochten ist, verharrt das Wissenschaftssystem im geistes- und kulturwissenschaftlichen Bereich - wenn auch nicht in der Klimafolgenforschung - auf dem Weltbild und dem Informationsstand der frühen sechziger Jahre. Der Blick in die Welt ist zwar dank neuer Kommunikationsmöglichkeiten und Datenflüsse im Gefolge der vierten Phase beschleunigter Globalisierung prinzipiell wesentlich erleichtert; doch bleibt unser mentales Kartennetz noch immer an jenem Meridian ausgerichtet, der schon für Goethes Blick auf die Weltliteratur prägend war: „Im Bedürfnis von etwas Musterhaftem müssen wir immer zu den alten Griechen zurückgehen.“17

15 Vgl. Ashcroft, Bill / Griffiths, Gareth / Tiffin, Hellen: The Empire writes back. Theory and practice in post-colonial literatures. London - New York: Routledge 1989.

16 Vgl. Ette, Ottmar: Asymmetrie der Beziehungen. Zehn Thesen zum Dialog der Literaturen Lateinamerikas und Europas. In: Scharlau, Birgit (Hg.): Lateinamerika denken. Kulturtheoretische Grenzgänge zwischen Moderne und Postmoderne. Tübingen: Gunter Narr Verlag 1994, S. 297-326.

17 Eckermann, Johann Peter: Gespräche mit Goethe in den letzten Jahren seines Lebens. Herausgegeben von Fritz Bergemann. Bd. I. Frankfurt am Main: Insel Verlag 1981, S. 211 f. 
Sie sehen also: Auch für das 18. Jahrhundert und selbst noch im 19. Jahrhundert ist es keineswegs eine ausgemachte Sache, dass der kulturelle Meridian nicht mehr durch die griechische Antike verläuft, die alten Griechen also aufgehört hätten, die unübertrefflichen und überzeitlichen Vorbilder kultureller und ästhetischer Entwicklungen im weltweiten Maßstab zu sein! Doch lassen Sie uns an dieser Stelle zurück zu Montesquieus Lettres persanes gehen, indem ich Ihnen wie in dieser Vorlesung üblich - zunächst einige Biographen ihres Verfassers vorstellen darf, die in Verbindung mit dem behandelten literarischen Werk stehen.

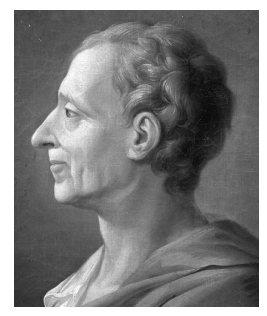

Abb. 17: Charles de Secondat, Baron de Montesquieu (1689-1755).

Montesquieu, ${ }^{18}$ genauer Charles-Louis de Secondat, Baron de La Brède et de Montesquieu, wurde ein Jahrhundert vor der Französischen Revolution am 18. Januar 1689 auf Schloss La Brède bei Bordeaux getauft und starb am 10. Februar 1755 in Paris. Der künftige Schriftsteller und Staatstheoretiker der französischen Aufklärung stammt aus einer Familie, die als Teil der sogenannten „Noblesse parlementaire“ nicht dem Feudaladel angehörte, für dessen Interessen Montesquieu später durchaus eintrat. Als Erstgeborener verbrachte er seine Kindheit auf Schloss und Landgut La Brède, das seine Mutter in die Ehe mit einem Sohn aus altadeliger Familie eingebracht hatte. Seine prägende Erziehung erhielt der junge Montesquieu als Internatsschüler bei den Oratorianern von Juilly bei Paris und damit in einem Umfeld, das für seinen kritischen Geist bekannt war. Einen solchen sollte er ein ganzes Leben pflegen. Aus jener Zeit im Internat stammt ein historisches Drama, das die literarischen Interessen des jungen Montesquieu bezeugt. Sein gesamtes Lebenswerk sollte sich im Spannungsfeld von Literatur und Philosophie bewegen ${ }^{19}$.

Nach juristischem Studium in Bordeaux wurde er im Jahr 1714 Rat, 1716 dann Vizepräsident am Gerichtshof der Guyenne, Ämter, in die sich bereits sein Großvater eingekauft hatte und die im Familienbesitz geblieben waren. 1726 verkaufte

18 Vgl. Böhlke, Effi / François, Etienne (Hg.): Montesquieu. Franzose, Europäer, Weltbürger. Berlin: Akademie Verlag 2005; sowie Hereth, Michael: Montesquieu zur Einführung. Wiesbaden: Panorama 2005.

19 Vgl. hierzu auch Starobinski, Jean: Montesquieu. Paris: Seuil 1953. 
der Baron das Amt wieder. Nach seiner Heirat 1715 mit einer Tochter aus einer reichen Hugenottenfamilie und der Geburt mehrerer Kinder pflegte Montesquieu weiter seine Kenntnisse in verschiedensten Wissensgebieten. Als Richter veröffentlichte er nach dem Tod von Louis-le-Grand eine wirtschaftspolitische Denkschrift über die Staatsschulden, die ihn als Kenner der Materie auswies. Bereits im Folgejahr 1716 wurde er in die Akademie von Bordeaux aufgenommen und tat sich durch mehrere Denkschriften hervor.

Sein eigentlicher literarischer Ruhm basierte freilich auf jenem Briefroman, mit dessen Niederschrift er wohl ab 1717 begann und den er 1721 anonym in Amsterdam veröffentlichte. Es dauerte nicht lange, bis die französische Zensur einschritt und das Werk verbot, eine Erfahrung, die Montesquieu noch mehrfach in seinem Leben machen sollte. Doch hat dies den Erfolg seines Werkes niemals ernsthaft gefährdet. Als Mitglied der Académie des Sciences von Bordeaux war Montesquieu zeitweise aber auch an naturwissenschaftlichen Problemen stark interessiert. Doch die Literatur bot ihm ausgedehntere und weiter gefächerte Erprobungsmöglichkeiten seines Denkens. Wahrscheinlich ist die Histoire véritable, die 1902 auf Schloss La Brède entdeckt wurde, eine Erzählung im Stile orientalischer Märchen, noch vor den Lettres persanes entstanden. Diese Persischen Briefe aber avancierten rasch zu einem Schlüsseltext der Aufklärung, ermöglichten sie doch - wie wir noch sehen werden - ihrem Lesepublikum, gleichsam ,von außen' auf den französischen Staat und auf die Sitten in Paris zu blicken, aber auch neugierige Blicke hinter die Mauern persischer Harems zu werfen. So war für jeden Geschmack etwas dabei!

Der große Erfolg dieses satirischen Briefromans veranlasste Montesquieu, des Öfteren Paris zu frequentieren, wo er Zugang zu wichtigen Salons und zur Sociéte de l'entresol fand. Montesquieu wurde so zu einem Teil frühaufklärerischer Kommunikationszirkel und setzte seinen intellektuellen Bildungsweg unbeirrt von seinen Ämtern und Verpflichtungen fort. Nach dem erwähnten Verkauf seines Richteramtes wurde er 1728 im zweiten Anlauf in die Académie Française gewählt und machte Paris zu seinem regelmäßig besuchten Fensterplatz mit Blick auf die Welt. Doch genügte ihm dies nicht.

Von 1728 bis 1731 reiste der französische Baron durch Europa, neben Deutschland und Holland unter anderem nach England, dessen politische Verfassung ihn - wie etwa gleichzeitig auch den Abbé Prévost oder Voltaire - machtvoll anzog. 1730 wurde er als „Fellow“ in die Royal Society sowie weitere britische Zirkel gewählt und damit auch Teil eines europäischen Kommunikationsnetzes, das sich noch durch seinen Beitritt zu einer Freimaurerloge erweiterte. 1731 kehrte er nach La Brède zurück, wo er sich fortan überwiegend aufhielt. Bereits in seinen Considérations sur les causes de la grandeur des Romains et de leur décadence von 1734, also seinen Betrachtungen über die Ursachen der Größe der Römer und ihres Nie- 
dergangs, verzichtete Montesquieu auf eine teleologische Geschichtsdeutung, die zuletzt Bossuet sanktioniert hatte, und hob den Einfluss materieller Umstände auf das Schicksal von Nationen hervor. Dabei unternahm er den Versuch, gesetzmäßige Abläufe innerhalb des Lebens von Staaten und Reichen herauszuarbeiten, wobei seine Überlegungen auch geharnischte Kritik am Staat von Louis XIV enthielten.

Dieser gegen jede Teleologie gerichtete Ansatz wird in Montesquieus nächstem Werk weiterentwickelt, aber selbstkritisch auch fragwürdig gemacht. Sein zweifellos wichtigstes und bis heute vieldiskutiertes Werk wurde nach zwölfjähriger Arbeit die Studie mit dem Titel De l'esprit des lois oder Vom Geist der Gesetze, die 1748 in Genf erschien. Ohne an dieser Stelle ausführlich auf die Überlegungen Montesquieus eingehen zu können, sei doch vermerkt, dass dort - zum Teil basierend auf Vorstellungen von John Locke - allgemeine Prinzipien der Gewaltenteilung zwischen Legislative, Judikative und Exekutive formuliert wurden. Derartige Prinzipien waren seit Ausgang des 18. Jahrhunderts etwa in den Vereinigten Staaten von Amerika modernen Staatswesen westlichen Typs eigen und bestimmen noch heute unsere Demokratien in Europa. Man übertreibt gewiss nicht, wenn man behauptet, dass Montesquieu die vielleicht wichtigsten Prinzipien moderner Staatswesen erdachte. Es ist in diesem Zusammenhang nicht uninteressant, dass De l'esprit des lois bereits 1751 auf den berüchtigten Index Librorum Prohibitorum kam und in dieser ehrenvollen Liste von der katholischen Kirche verbotener Bücher bis zur Abschaffung des Index vor einem halben Jahrhundert, im Jahre 1967, verblieb.

Der Moralist und Staatsphilosoph Montesquieu erlangte epochale Bedeutung als Autor des in seiner Zeit sehr verbreiteten Romans Temple du Gnide von 1725 wäre er wie andere Autoren einer späten Preziosität heute in der Tat vergessen. Ähnliches gilt freilich nicht, wenn wir uns auf die Lettres persanes besinnen, die ihn als großen Schriftsteller ausweisen, der früh schon wesentliche Formulierungen seines Denkens erprobte. Montesquieu blieb seinem Weg im Spannungsfeld zwischen Literatur und Philosophie treu; und es macht wenig Sinn, ihn entweder auf die eine oder die andere Seite zu zerren. Denn die Literatur bot - gerade im Bereich des Briefromans - Montesquieus Denken Spiel-Räume, die ihm ein philosophisches Schreiben nicht offerieren konnte.

In seinen Pensées et fragments, die erst zwischen 1899 und 1901 erschienen, sowie seinen Cahiers, die schließlich 1941 veröffentlicht wurden, blicken wir dem späten Montesquieu über die Schulter, der weiter an seinen Hauptgedanken arbeitete, sich nun aber weniger Rücksichten aufzuerlegen brauchte. Seine letzten Lebensjahre waren von seiner zunehmenden Erblindung gekennzeichnet, wobei ihn seine jüngste Tochter bei der Abfassung letzter Schriften und Beiträge unterstützte - unter anderem auch für die große Encyclopédie von Diderot und D’Alembert. Mancherlei Ausfälle gegen den „Plagiator“ Voltaire sind noch überliefert. Doch dieses Grummeln ist längst verhallt. Montesquieu verstarb nicht auf seinem 
Schloss La Brède, sondern in Paris, wohin er noch ein letztes Mal hatte fahren wollen.

Ohne jemals ein Revolutionär zu sein, wirkte Montesquieus Lehre von der Gewaltenteilung stark auf die revolutionäre Ideologie ein - zumindest solange die „Montagnards“ nicht die Macht an sich gebracht und die politische Theorie Montesquieus durch Rousseaus Konzept der unteilbaren und nicht übertragbaren Volkssouveränität ersetzt hatten. Mit seinem Denken trat er einer teleologisch bestimmten Universalgeschichte entgegen und für die Eigengesetzlichkeit kultureller Entwicklungen ein. Diesen offenen Geist atmen auch die Briefe seines 1721 veröffentlichten literarischen Hauptwerks.

Beschäftigen wir uns also mit jenem Werk, das den jungen Montesquieu berühmt machte ${ }^{20}$, wenn er sich auch als Autor dieser Briefe erst einige Jahre später zu erkennen gab: Die Lettres persanes erschienen anonym, und sie trafen auf ein ungeheures Publikumsinteresse. Die Folge war, dass noch im selben Jahr 1721 eine ganze Serie weiterer Ausgaben erschien. Die Forschungen haben ergeben, dass innerhalb eines Jahres mindestens sechzehn verschiedene Ausgaben und „contrefaçons“ dieses Textes publiziert wurden - eine durchaus beeindruckende Zahl. Vergegenwärtigen wir uns kurz den zeithistorischen Kontext in Frankreich!

Nach dem Tod von Louis XIV im Jahre 1715 hatte die Régence die Herrschaft übernommen, doch sah sie sich zunehmend einer öffentlichen Kritik an ihrer Führungsrolle ausgesetzt. Diese historischen Ereignisse werden unsere Perser, die Anfang des Jahres 1711 aus der schönen und legendenumwobenen Stadt Isfahan aufgebrochen und im Mai 1712 in Paris eingetroffen waren, aufmerksam aus ihrer vermeintlich ,exotischen“ Perspektive kommentieren und kritisieren. Denn im Grunde schlüpfen die von Montesquieu Erfundenen in die Rolle von Aufklärern, ist Kritik doch ihr zentrales Verfahren und Anliegen, um mit den französischen Verhältnissen umzugehen. Ich darf Ihnen Kants Aussage fast schon im Rückblick auf das gesamte 18. Jahrhundert in Erinnerung rufen: „Unser Zeitalter ist das eigentliche Zeitalter der Kritik, der sich alles unterwerfen muß.“21 Dies galt auch für Frankreich, seine politischen wie seine kulturellen Institutionen.

Die beiden persischen Reisenden oder Besucher werden bis November 1720 bleiben und das gesellschaftliche Leben der Franzosen aus den verschiedensten Blickwinkeln und einer grundsätzlichen Außerhalbbefindlichkeit betrachten und kritisch kommentieren. Die sich in dieser Konstellation abzeichnende Gesellschaftsund Religionskritik machte es erforderlich, 1721 einen imaginären Verlagsort, nämlich Köln, und einen imaginären Verleger, nämlich Pierre Marteau anzugeben - der

20 Vgl. u. a. Firges, Jean: Montesquieu: „Die Perserbriefe“. Sonnenberg: Annweiler 2005. 21 Kant, Immanuel: Kritik der reinen Vernunft, S. 9. 
Peter Hammer Verlag in Wuppertal hätte sich gefreut. Tatsächlich aber hieß der Verleger Jacques Desbordes, auch er im Ausland ansässig, freilich weder in Köln noch in Isfahan, sondern im nahen und für die Aufklärungsliteratur so wichtigen Amsterdam.

Der große Erfolg des Buches war so überraschend nicht, denn alles, was aus dem Orient kam, war damals beliebt. Man könnte hier mit Edward Saïd von einem französischen Orientalism des 18. Jahrhunderts sprechen, wobei wir uns mit dieser Fragestellung noch später beschäftigen wollen. Doch sei bereits an dieser Stelle festgehalten, dass der Orient - in seiner weiten Begriffsbedeutung, wie er für das französische Aufklärungsjahrhundert charakteristisch ist - so etwas wie den Prototyp des Anderen darstellte. Denn für das Siècle des Lumières repräsentierte der Orient das Fremde, also die Alterität schlechthin, war also zugleich Herausforderung und Abgrenzung einer sich neu konstituierenden kollektiven Identität Frankreichs und - unter dem Einfluss Frankreichs - Europas überhaupt. Abendland und Morgenland standen einander als Bilder absoluter Alterität gegenüber.

Die Quellen für dieses Interesse am Orient und an Asien speisten sich aus den berühmten Berichten der Jesuiten aus dem ,Reich der Mitte‘, des sprichwörtlichen ,Kaisers von China', sowie - mit Blick auf Persien - aus zeitgenössischen Reiseberichte der zweiten Hälfte des 17. Jahrhunderts. In der Tat enthalten auch die Lettres persanes eine ganze Reihe von Zügen, die diesen Text nicht nur mit der Tradition des Briefromans und des späteren „conte philosophique“, sondern gerade auch mit der zeitnahen Reiseliteratur verbinden. Dies ist wichtig und aufschlussreich auch hinsichtlich jener Reiseberichte, die wir uns mit Blick auf Amerika noch anschauen werden: Nicht allein für die Aufklärungsliteratur spielt die europäische wie außereuropäische Reiseliteratur eine entscheidende Rolle ${ }^{22}$.

Vergessen dürfen wir aber auch nicht den großen Erfolg von Tausendundeiner Nacht gerade in Frankreich, wo diese Sammlung von weit über den arabischen Raum hinausreichenden Erzählungen das Bild des Orients auf Dauer nicht unwesentlich mitprägte. Vor diesem Hintergrund wird deutlich, warum Montesquieu auf jeden Fall seinen Lesern einen Harem und ein Serail mit der Darstellung ausgefeilter Sinnlichkeit orientalischer Prägung bieten musste: Er knüpfte gleichsam an die Rolle der Scheherazade in Tausendundeiner Nacht an. Freilich handelt es sich, wie man formulieren könnte, um einen diskreten Erotismus, der niemanden - auch nicht die Kirche - verschrecken sollte und die Leserinnen und Leser nur ein wenig kitzelte.

Das literarische Verfahren des Rückgriffs auf Ausländer aus weit entfernten Ländern zur Gewinnung einer Position, die gleichsam von weit draußen die eigene

22 Vgl. hierzu den ersten Band der Reihe „Aula“, folglich Ette, Ottmar: ReiseSchreiben (2020). 
Gesellschaft kritisch unter die Lupe nehmen sollte, war - wir haben es schon erwähnt - nicht neu. Montesquieu gab diesem Procedere lediglich eine andere, vielleicht die entscheidende und für das 18. Jahrhundert charakteristische Form überhaupt. Zuvor schon hatte man auf Chinesen, Siamesen, einen türkischen Spion, einen Sizilianer oder auch einen Perser zurückgegriffen, so dass sich die Lettres persanes fraglos architextuell, also auf Ebene der Gattung, einer eigenen literarischen Tradition zuordnen konnten. Die Leserschaft war mit dieser Sub-Gattung schon etwas vertraut.

Allerdings gilt es schon jetzt festzuhalten, dass die orientalische Fiktion bei Montesquieu außerordentlich und ungewöhnlich subtil und liebevoll entfaltet wurde. So umfasst der erste Teil der Briefe zunächst einmal eine Selbstsicht des Orients aus der Feder des großen Usbek, aber auch anderer Orientalen wie etwa Eunuchen, Haremsfrauen, Sklaven, begüterte Freunde und vieler Figuren mehr. Mit länger werdender Aufenthaltsdauer in Frankreich können wir in Usbek die frühe Form eines Kosmopoliten, eines Weltbürgers erkennen. Dieser setzte sich zunehmend über die engen Grenzen seiner eigenen Welt, die er von Beginn des Textes an explizit sprengen wollte, hinweg und entwickelt Maßstäbe einer allgemeinen Vernunft, die den Vorstellungen späterer Philosophen wie Voltaire, Immanuel Kant, Georg Forster oder anderer Vertreter der Aufklärung nicht allzu ferne blieben. Darüber hinaus ist Usbek nicht nur Weltbürger, sondern auch ein Mann von Welt.

Natürlich, Sie haben Recht: Wir sind im Jahre 1721, befinden uns noch immer in der Frühaufklärung, und unser Perser ist selbstverständlich ein europäisches Geschöpf, dessen Universalisierung gewiss nur eine vorgegebene Spiegelung aus europäischer Perspektive ist! Usbek und mit ihm sein realer, textexterner Autor wie seine Leserinnen und Leser suchen aber nach einer universellen Wahrheit, nach einem universellen Maßstab. Dies ist die zentrale Linie des Buches, die alle ihre einzelnen Episoden und Aspekte miteinander verbindet. Die Lettres persanes sind ein literarischer Brennspiegel, in welchem sich nicht nur zentrale Elemente der Frühaufklärung, sondern der Aufklärung insgesamt konzentrieren.

Intertextueller Hintergrund für Montesquieus Entwurf waren natürlich die umfangreichen Lektüren des jungen Franzosen aus der Region um Bordeaux, der seinen Descartes ebenso kannte wie Bayle, Fontenelle und viele Reiseberichte des 17. wie des beginnenden 18. Jahrhunderts. Die literarische Gattung des Briefromans gab ihm die fiktionalen Möglichkeiten an die Hand, mit diesen Philosophemen anderer nicht-fiktionaler Texte zu experimentieren und zu jonglieren. Gerade die Reiseberichte seiner Zeit waren eine unverzichtbare Schatztruhe für ihn. Übrigens sollte er selbst einen Bericht von seiner eigenen großen Reise quer durch Frankreich, den Norden Italiens, den Süden Deutschlands, das Rheinland und vor allem England veröffentlichen und damit zu dieser im 18. Jahrhundert so beliebten Gattung beitragen. 
Die literarische Reise, die der junge Montesquieu mit seinen Helden in den Lettres persanes antreten sollte, konnte zunächst keinen Autornamen dulden, sondern stellte eine Weltreise auf dem Fußboden, den Balken seines südwestfranzösischen Schlosses von La Brède dar, in das er die Welt mit Hilfe seiner Lektüren und seines Schreibens hineinholte. Montesquieus familiär vorgezeichneter Weg als Jurist ließ ihn eine berufliche Karriere anstreben, zu der ein derartiges fiktionales Buch nicht passen zu können schien. So sollte er entschuldigend bereits in seiner „Introduction“ schreiben, er wolle seinen Namen nicht preisgeben, da sein Buch mit seinem Charakter nicht in Übereinstimmung stehe; man müsse ihn ansonsten mit guten Gründen fragen, ob er sich seine Zeit nicht mit Besserem, Ernsthafterem und Wichtigerem vertreiben könne als eben mit der Abfassung eines Briefromans.

Allerdings: Als politischer Moralist erweist sich Montesquieu auch in seinen Lettres persanes! Eine Untersuchung der Montesquieu in seiner Bibliothek zur Verfügung stehenden Werke ergab, dass sich der junge Südwestfranzose sehr wohl mit den unterschiedlichsten Aspekten seiner orientalischen Fiktionen mit intertextueller Hilfe von Reiseberichten, aber auch zahlreicher philosophischer und moralischer Abhandlungen vorbereitet hatte. Für einen juristisch ausgebildeten Verwaltungsbeamten der französischen Monarchie war allein der fiktionale Status seines Schreibens überraschend - zumindest auf den ersten Blick. So ließe sich auch die These verteidigen, dass die Lettres persanes zwischen Ende 1717 und Ende 1720 durchaus in Übereinstimmung mit Montesquieus ,eigentlichen` Tätigkeitsfeldern verfasst wurden.

Ausgangspunkt der gesamten Fiktion ist der Entschluss eines begüterten, der Wahrheit und Offenheit verpflichteten Orientalen, der durch seine Tugend am Hofe des Prinzen von Isfahan zunehmend in Schwierigkeiten gekommen war, gemeinsam mit einem enthusiastischen und noch bildungsfähigen jungen Mann nach Paris zu reisen. Dort wollte er die Sitten der abendländischen Welt und, wie er seinem Fürsten sagt, die Wissenschaften des Okzidents aus eigener Anschauung und Erfahrung kennenlernen. Der etwa neunjährige Aufenthalt in Europa wird dabei keineswegs aus einer gleichbleibenden Perspektive geschildert. Vielmehr machen Usbek und sein junger Begleiter Rica selbst persönliche Entwicklungen durch, in denen eine monokulturelle Ausrichtung in zunehmendem Maße hinterfragt und der Kritik ausgesetzt wird.

Gerade aus dieser sich verändernden Perspektive ist es konsequent, dass die enorme Distanz zum Christentum sich im Verlauf dieser Jahre zwar bedeutend verringert, es aber keineswegs zu einer religiösen Konversion und damit zum Triumph des Christentums kommt, auch wenn eine solche natürlich nicht unspektakulär zu inszenieren gewesen wäre. Der reife und selbstreflexive Usbek kennt am Ende seines Aufenthalts in Paris, als er nach dem Tode Roxannes nach Persien zurückkehrt, verschiedene Welten, ohne doch zu wissen, welche von diesen Welten die 
bessere wäre. Wir könnten in Usbek nicht nur einen Weltbürger, sondern vor allem einen transkulturellen Vertreter einer Spezies erblicken, deren unterschiedliche Kulturen querende Entwicklung just im 18. Jahrhundert ihren eigentlichen Ausgangspunkt nahm.

Daher auch die genaue Beobachtung des Orients durch einen vorgeblichen Orientalen selbst, die den ersten Teil der Briefsammlung einnimmt. Denn erst durch die Bestimmung des eigenen Herkunftsortes wird eine (transkulturelle) Bewegung überhaupt erst möglich: Die Beschreibung des ,Eigenen“ - bei der sich Montesquieu auf die ihm zur Verfügung stehenden ,Quellen' bezog - geht der Beschreibung des aus Usbeks Sicht ,Anderen“ voraus. Damit wird der (mono-)kulturelle Hintergrund geschaffen, der als Folie zunächst die interkulturellen Möglichkeiten entstehen lässt und schließlich zu einer transkulturellen Bewegung führt - auch wenn diese lediglich als Entwurf, als Projektion existiert, da es sich ja nicht ,wirklich' um die Reise eines Persers nach Europa handelt.

Montesquieu kam in den folgenden Jahrzehnten aufgrund seines Briefromans mehrfach unter Beschuss; gerade aus jenen Kreisen, die sich ihrer Wahrheiten sicher glaubten und andere als monokulturelle Dogmen nicht hinzunehmen gewillt waren. Wir sind in unserem 21. Jahrhundert mit derartigen Gruppen wohlvertraut sie haben immer Hochkonjunktur, ob im beginnenden 18. Jahrhundert oder aber in unserer Gegenwart, und sie sterben auch niemals aus. Beispielsweise hatte noch 1751, also drei Jahrzehnte nach dem erstmaligen Erscheinen des Briefromans, der Abbé Gaultier Montesquieu in seinen Lettres persanes convaincues d'impiété direkt angegriffen, so dass sich Montesquieu in einem kurzen Text, der wohl unmittelbar danach entstand, eindrucksvoll wehrte.

Es handelte sich um einen Text, den er als „Supplément“ seiner Ausgabe von 1754 - also kurz vor seinem Tod im Jahr 1755 - beigab und der seitdem wohl den allermeisten Ausgaben der Lettres persanes vorausging. Ich möchte diesen wichtigen paratextuellen Hinweisen folgen, die unter dem Titel „Quelques réflexions sur les Lettres persanes“, mithin „Einige Gedanken zu den Lettres persanes“, abgedruckt wurden. Schauen wir uns deren Beginn einmal näher an:

Nichts hat in den Lettres persanes mehr Gefallen erregt als dass man darin, ohne daran zu denken, eine Art Roman finden konnte. Denn man sieht hier den Beginn, die Fortschritte und das Ende. Die verschiedenen Figuren sind in eine Kette hineingestellt, die sie miteinander verbindet. In dem Maße, in dem sich ihr Aufenthalt in Europa verlängert, nehmen die Sitten in diesem Teile der Welt in ihrem Kopfe einen weniger wunderbaren und weniger bizarren Anstrich an, sie sind mehr oder minder frappiert vom Bizarren und Wunderbaren, wobei sie der Differenz zwischen ihren jeweiligen Charakteren folgen. Auf der anderen Seite wächst in Asien das Durcheinander im Serail in dem Maße, in dem sich die Abwesenheit von Usbek verlängert, das heißt in dem Maße, in welchem die Wut zunimmt und die Liebe abnimmt. 
Im Übrigen gelingen diese Spielarten des Romans gewöhnlich, weil man sich selbst von seiner aktuellen Situation Rechenschaft ablegt; was die Leidenschaften stärker fühlen lässt als alle Berichte, die man darüber verfassen könnte. Dies ist einer der Gründe für den Erfolg bestimmter charmanter Werke, welche seit den Lettres persanes erschienen sind.

Schließlich können Digressionen in den gewöhnlichen Romanen nur erlaubt sein, wenn sie selbst einen neuen Roman bilden. Man dürfte darunter keine Räsonnements mischen, weil keine der Figuren zum Räsonieren angelegt wurde und weil dies gegenläufig zur Zielsetzung und zur Natur dieses Werkes wäre. Aber in der Form von Briefen, wo die Handelnden nicht gewählt werden und wo die behandelten Gegenstände von keiner Absicht und von keinem vorgefassten Plane abhängen, da hat sich der Autor den Vorteil verschafft, seinem Roman Philosophie, Politik und Moral beifügen und alles mit einer geheimen und in gewisser Weise unbekannten Kette verbinden zu können. ${ }^{23}$

In diesen vielleicht ein wenig umständlichen Worten mag nicht nur der Stolz von Montesquieu deutlich werden, in seinen jungen Jahren ein Werk geschaffen zu haben, das sich noch immer eines großen Erfolges beim Publikum rühmen durfte, sondern auch seine literarische Sensibilität, mit welchen er den eigentlichen Plan und die Konstruktionsprinzipien seines romanesken Textes beleuchtet. Denn die Lettres persanes bilden gemäß der Einschätzung ihres mehr für seine Philosophie berühmten Autors eine Art Roman, wobei unter dem Gattungsbegriff zu Beginn des 18. Jahrhunderts keineswegs jene Form der „bürgerlichen Epopöe“ zu denken ist, von der Georg Wilhelm Friedrich Hegel ein gutes Jahrhundert später sprechen sollte. Der Roman war vielmehr im Jahrhundert der Aufklärung jene literarische Form, die sich nicht an der Gesetzlichkeit des „vraisemblable“, des Wahrscheinlichen, auszurichten brauchte, es also nicht auf die Erzielung von Glaubwürdigkeit abgesehen haben musste.

Daraus entwickelt der angeführte Paratext im Rückblick eine Grundstruktur des Narrativen, die in Lexem-Rekurrenz als Kette, als „chaîne“ erscheint, eine wichtige Metapher, die gleich wenige Zeilen später ein zweites Mal in Erscheinung treten sollte, um das geheime Band, die geheime Verbindung zu signalisieren, welche alle Elemente in diesem Text zusammenhalten konnte. Die Ingredienzien dieser „espèce de roman“ sind freilich gattungsuntypisch, denn sie stammen allesamt aus ,höheren'Sphären, die normalerweise - oder ordinärerweise - in den Romanen der damaligen Zeit nichts zu suchen hatten. Denn nach Montequieus Plan sollten Philosophie, Politik und Moral in diesen Briefen, diesen „lettres“, mit einer romanesken Grundstruktur narrativ verbunden werden.

In diesem Zusammenhang ist unübersehbar, dass die durchaus ernste Anlage für eine breitere Leserschaft bei aller Leseerfahrung mit viel Reizvollem im

23 Montesquieu, Charles de Secondat, Baron de: Quelques réflexions sur les Lettres persanes. In (ders.): Lettres Persanes. Texte établi par André Lefèvre. Paris: A. Lemerre 1873, Bd. 1, S. $1 \mathrm{f}$. 
Stile des 18. Jahrhunderts gewürzt werden sollte. Doch alles musste mit Hilfe einer unsichtbaren, unbekannten Kette in seinem Innersten zusammengehalten werden. Entscheidend aber ist, so scheint mir, dass hier aus der Fiktion von Reise, aus der Fiktion interkultureller Begegnung, eine Geschichte entsteht, die in der Tat als transkulturelle Bewegung und Begegnung verstanden werden könnte. Damit ist selbstverständlich keine authentische Erfahrung mit unterschiedlichen Kulturen gemeint; und natürlich konnte sich daraus auch keine transkulturelle Gesellschaft entwickeln, weder in diesem Text noch außerhalb seiner Grenzen. Wir haben es ja schließlich mit einer Fiktion zu tun ...

Aber eben mit der Fiktion einer transkulturellen Begegnung. Und folglich mit der Fiktion einer erlebten Erfahrung, welche als literarischer Erprobungsraum für künftige Erfahrungen in der Realität dienen konnte und - so darf man wohl hinzufügen - auch dienen sollte. Denn was in der Literatur gelebt und erlebt werden konnte, war nichts anderes als ein Experimentierfeld, ein literarisches Labor für das Erleben in konkreten gesellschaftlichen Situationen. Oder mit anderen Worten: Was in der Literatur gelebt werden konnte, das konnte eines Tages auch in der Realität gelebt werden. Und die Leserinnen und Leser der Lettres persanes sollten dieses Lebenswissen und Erlebenswissen bereits zu ihrer Verfügung haben und diese Lese-Erfahrungen machen können. ${ }^{24}$

Aktualität, Vielfalt an Einsichten, Differenzerfahrung sowie Inter- und Transkulturalität sind entscheidende Vorgaben, die in literarischem Gewand in diesem Paratext bereits erscheinen. Und von Beginn an auch der Verweis auf den Harem, den Serail, der natürlich bei der zeitgenössischen männlichen wie weiblichen Leserschaft ein enormes emotionales und erotisches Potential in Bewegung setzen konnte, wollte und sicherlich auch sollte. Übrigens sind von insgesamt sechzig Briefen, die dem Orient gewidmet sind, nicht weniger als vierzig auf den Serail bezogen. Darin wiederum nehmen der Eunuch und die Haremsfrau die zentralen Stellungen ein. Dies führt zu einer enormen Bedeutung, die gerade dem Serail bezüglich Breite und Intensität der Lektüreerfahrung im Rahmen der Lettres persanes von Anfang an zukommt.

Ich möchte Ihnen dies sogleich an dieser Stelle in aller Kürze zeigen, weil in derartigen Kontexten die Außerhalbbefindlichkeit und die spezifischen Verfahren Montesquieus außerordentlich deutlich zutage treten. Nehmen wir als erstes den dritten Brief der Sammlung, einen Brief von Zachi, einer der jungen Frauen, die Usbek in seinem herrschaftlichen Serail in Isfahan zurückließ, an ihren mittlerweile auf der Reise nach Paris befindlichen Gatten, dem sie ihre Liebe nach-

24 Vgl. hierzu Ette, Ottmar: ÜberLebenswissen. Die Aufgabe der Philologie. Berlin: Kulturverlag Kadmos 2004. 
schickt. Diese Passage gibt gleichsam den erotischen Grundton für den gesamten Briefroman vor. Es ist eine gebremste Erotik: Das 18. Jahrhunderts sollte auf diesem Gebiet nicht nur beim Marquis de Sade ganz andere Töne anschlagen. Doch ist die bei Montesquieu entfaltete Erotik nicht nur gebremst, sie war zugleich eine andere Erotik oder mehr noch eine ,Erotik des Anderen“, in welcher das Andere zugleich als verführerisch und verachtenswert, in jedem Falle aber höchst verlockend erscheinen und wohl seiner Kleider, nicht aber seiner kulturellen Dimension entkleidet werden kann:

\begin{abstract}
Bisweilen sah ich mich an diesem Ort, wo ich Dich zum ersten Male in meinem Leben in meinen Armen empfangen habe; bisweilen an jenem, wo Du die berühmte Auseinandersetzung zwischen Deinen Frauen entschiedest. Jede einzelne von uns fühlte sich den anderen an Schönheit überlegen. Wir präsentierten uns vor Dir, nachdem wir alles erschöpft hatten, was die Einbildungskraft an Putz und Schmuck zu liefern vermag. Lustvoll sahst Du die Wunder unserer Kunst; Du bewundertest, wie weit uns die hitzige Glut, Dir zu gefallen, getrieben hatte. Aber Du verfügtest bald, dass diese geborgten Reize den Platz einer natürlicheren Anmut überließen: Du zerstörtest unser ganzes Werk. Wir mussten uns dieses Schmuckes entkleiden, welcher Dir unbequem geworden war; wir mussten vor Deinen Augen in der Einfachheit der Natur erscheinen. Ich hielt die Scham für nichts; ich dachte nur an meinen Ruhm. Glücklicher Usbek, wie viele Reize wurden vor Deinen Augen ausgebreitet! Wir sahen Dich lange von Verzauberung zu Verzauberung irren: Deine ungewisse Seele schwankte lange, ohne sich festzulegen; jeder neue Reiz forderte von Dir einen Tribut; in einem gewissen Moment waren wir alle von Deinen Küssen bedeckt; Du trugst Deine neugierigen Blicke an die verborgensten Orte; Du ließest uns in einem Augenblick in tausenderlei verschiedenen Stellungen erscheinen: immer neue Befehle und ein immer neuer Gehorsam. ${ }^{25}$
\end{abstract}

Wir sollten uns in dieser Passage zunächst einmal die erzähltechnische, aber auch die kulturelle Ausgangssituation vor Augen führen. Dabei ist es keine Frage, dass wir es hier mit erotischen Phantasien aus dem Blickwinkel eines männlichen Subjekts zu tun haben, eines Mannes, der sich aus westlicher Sicht in die Rolle eines männlichen Gebieters mit seinen tausend Frauen im Harem imaginiert und so seine erotischen Wunschvorstellungen auf das kulturell Andere projiziert. Dabei werden die kulturellen Dimensionen bald sogar insofern ausgeblendet, als die Frauen in ihrer Nacktheit, laut Text in der Einfachheit ihrer Natur, erscheinen müssen und so für den westlichen Betrachter noch leichter in allen möglichen Positionen imaginierbar sind.

Verdeutlichen wir uns die im französischen Briefroman evozierte Kommunikationssituation, die - und dies trug zum Erfolg des Romans nicht unwesentlich bei - mit einer gewissen erotischen Schlüpfrigkeit spielt. Eine der Frauen Usbeks schreibt in einem Brief wenige Wochen nach dessen Abreise aus Isfahan, einen

25 Montesquieu: Lettres persanes, Bd. 1, S. $10 \mathrm{f}$. 
Brief voller Zärtlichkeit und Unterwürfigkeit. Da diese Reise nach Frankreich ihren männlichen Gebieter auf Jahre in weite Entfernung von ihr und seinen Haremsdamen verbannt, schreibt ihm die schöne junge Frau, um ihn in der von Eunuchen bewachten Gesellschaft des Serail ihrer großen Liebe zu versichern und sich als seine Lieblingsfrau zu präsentieren.

Erzähltechnisch ist die Form des Briefes an den direkten Adressaten Usbek gewählt, eine schriftliche Kommunikationsform gleichsam von Perserin zu Perser. Gehen wir von der Tatsache aus, dass es sich bei Montesquieu um einen französischen Autor handelt, so stellen wir fest, dass wir es in diesem Brief mit einer doppelten Verlagerung oder Transposition zu tun haben. Einerseits wird in diesem Schreiben nicht die europäische Perspektive auf Dinge des Orients gewählt, sondern die Fiktion einer orientalischen Erzählerinnenposition, die über den Orient berichtet. Andererseits kommt es zugleich auch zu einer Verwandlung des Geschlechts, insoweit der männliche Autor jetzt die Erzählerposition einer weiblichen orientalischen Erzählerin wählt, welcher er freilich männliche Wunschträume in die Feder diktiert. Damit ist gleichsam ein Spiel mit einer doppelten, also kulturellen und genderspezifischen Alterisierung in Gang gesetzt, das männliche Leser wie weibliche Leserinnen im Frankreich des 18. Jahrhunderts zu fesseln vermag.

Die geschlechtliche Verwandlung wird zudem insoweit in diesem Schreiben stark akzentuiert, als in diesem dritten Brief sich sogleich die anderskulturelle Bewertung von Geschlechtlichkeit den Blicken nicht des orientalischen Gebieters, sondern des europäischen Lesepublikums zeigt und preisgibt. Wir haben es mit einer erotischen Auswahlsituation in einem persischen Serail zu tun, die von einem Westeuropäer auf der Grundlage europäischer Reiseberichte erfunden und in ein bestimmtes Vokabular der Zeit, in ein Vokabular der Aufklärungsepoche, gekleidet wurde. Dabei gewährt die orientalische Erzählerin nicht nur tiefe Einblicke gleichsam in ihre eigene Kultur, sondern auch in ihr eigenes Rollenverhalten, in ihr geschlechtliches Verhalten oder ihre Genderidentität. Diese freilich wird in den Farben einer ,Natürlichkeit' dargestellt, welche der Frau ein schamloses Schönheitsverhalten andichtet. Dieses Bild aber kann nur deshalb bei einer europäischen Leserschaft erfolgreich sein, weil es auf weiblichen Stereotypen nicht morgen-, sondern abendländischer Prägung beruht.

Wir sehen in dieser Passage nicht nur die Auseinandersetzung zwischen zwei als sehr unterschiedlich signalisierten kulturellen Positionen und den Gegensatz zwischen zwei klar voneinander getrennten Geschlechtern gemäß der biologischen Geschlechtlichkeit (Sex), sondern vor allem ein abweichendes Geschlechterverhalten im Umgang der Geschlechter miteinander. Die Differenz siedelt sich folglich auf einer kulturell bedingten Gender-Ebene an, welche interkulturell, im Dialog zwischen zwei verschiedenen Kulturen, vermittelt werden muss. So bringt Montesquieu nicht nur den Orient gleichsam zum Sprechen, sondern auch die Ori- 
entalin - und dass hierbei ein Vexierbild unterschiedlicher Geschlechterbilder entsteht, versteht sich von selbst. Wir können dies als doppeltes Bauchrednertum beschreiben, wobei die Kommunikationssituation des Briefeschreibens nun die innere psychische Verfassung der Briefeschreiberin vor Augen führt. Montesquieu knüpft dabei an das kulturell bedingte Lebenswissen seiner Leserschaft an.

Denn mit dieser Anlage wird zugleich eine Spannung gegenüber den Geschlechterrollen in Europa aufgebaut. Ihre eigentliche Würze erhält diese Passage ja gerade durch die Tatsache, dass in diesem Brief die Fiktion einer orientalischen Erzählerin, die über erotische Praktiken in Isfahan berichtet, mit einem europäischen, mit einem französischen Lesepublikum konfrontiert wird, welches sich gleichsam in den Voyeur dieser Szenerie verwandelt. Von diesem Punkt aus wird verständlich, wie nun der Körper-Leib selbst der Orientalin zum Objekt des männlichen und westlichen Begehrens wird. Denn die schöne junge Frau zeigt sich diesem europäischen Publikum zunächst verhüllt und vielfach geschmückt, dann aber plötzlich schamlos in aller Einfachheit ihrer Natur, also ohne jede Hülle, wohl aber im Kontext ihrer anderskulturellen Codes und Selbstverständlichkeiten. So wird der weibliche orientalische Körper zum Objekt westlichen Begehrens, eine Konstellation, die wir zumindest bis in die Mitte des 20. Jahrhunderts weiterverfolgen können. ${ }^{26}$

Damit wird die Wahrnehmung anderskultureller Praktiken raffiniert in den Mittelpunkt gerückt. Zugleich wird auch die männliche Psyche in Aktion vorgeführt, insoweit nun der männliche Briefdialogpartner als aktiver Zuschauer in Szene gesetzt wird. Denn er küsst nicht nur die Schönen seines Harems, sondern gibt seinen gehorsamen, ihm unterworfenen Frauen auch die unterschiedlichsten Situationen vor, die unterschiedlichsten Stellungen, in denen er sich seine weiblichen Liebesobjekte imaginiert. Seine neugierigen Blicke dringen selbst zu den verborgensten Orten der ihm dargebotenen weiblichen Körper vor. Dass wir es hier mit erotischen Träumen heterosexueller westlicher männlicher Subjekte zu tun haben, steht außer Frage.

Gleichzeitig ist dies aber eine Position, die von jener des Erzählers und gewiss auch des textexternen realen Autors nicht mehr sehr weit entfernt ist. Denn die imaginierte weibliche Erzählerin verweist auf eine männliche literarische Schreibinstanz, die wir nicht mit dem realen Autor verwechseln dürfen, die uns aber Hinweise auf diese reale Instanz gibt. So ließe sich anhand dieser Passage auch eine Poetik der Bewegungen jenseits der „parure“, jenseits des Schmucks und Zierrats herausfiltern, in der die Bewegungen der einzelnen Figuren deutlicher hervortreten. Entscheidend ist freilich auch in diesem Zusammenhang die inter- und trans-

26 Vgl. Said, Edward W.: Orientalism. New York: Vintage Books 1979. 
kulturelle Dimension, die es einmal mehr zu beachten gilt. Dabei ist mir wichtig, dass Sie sich mit der Verlagerung des Geschlechtlichen von der Ebene des biologischen Geschlechts (Sex) zur kulturellen Geschlechteridentität (Gender) beschäftigen und sich diesen Shift klarmachen. Denn er kann in solcher Stärke nur in Form einer doppelten Alterisierung funktionieren, die bereits oben herausgestellt wurde. Insofern hat die Projektion von Körperlichkeit und Kultur in eine außereuropäische Welt einen fundamentalen Bedingungszusammenhang. Und dieser steht in Verbindung mit der Tatsache, dass - und dies ist eine zentrale These dieser Vorlesung - Aufklärung als rein europäisches Phänomen nicht adäquat erfasst werden kann.

Daher könnten wir in dieser Körper-Leib-Dimension des objektivierten weiblichen Körpers noch eine weitere Figur erkennen, jene nämlich der Beziehungen zwischen Orient und Okzident, welche immer wieder ins Zentrum der Aussagen aller Briefschreiber gerückt werden. Das Körper-Haben der orientalischen Frau, die dem europäischen Lesepublikum vor Augen geführt wird, ist nicht unabhängig von einer Verfügbarmachung außereuropäischer Welten, die wir uns im weiteren Verlauf dieser Vorlesung noch näher anschauen werden. Denn die begehrte und unterworfene orientalische Frau verkörpert gleichsam figural die Verlockungen des Orients, der in der Figur des Weiblichen erscheint und damit jene orientalisierende Einfärbung erhält, die gleichsam zur Kolonisierung herausfordert: zur Inbesitznahme einer sich darbietenden Schönheit, die nur nach ihrem Herren und Gebieter verlangt.

Sie sehen: Die Lettres persanes haben es in sich! Und sie machen von Beginn an klar, dass Aufklärung in Europa stets die Dimensionen außereuropäischer Welten beinhaltet - und seien sie fiktional aufbereitet. Montesquieus Text ist als Briefroman außerordentlich breit angelegt, in seiner Gattungszugehörigkeit wie in seiner Themenvielfalt vielgestaltig und widersprüchlich, stets aber faszinierend und philosophisch anregend. Dabei ist das Leit-Schema der Briefanordnung sehr übersichtlich angeordnet. Dies gibt dem Brief-Konvolut die literarische Struktur eines Briefromans, basierend auf seiner strikten Chronologie, die am Ende stets die Briefe nach dem persischen Kalender datiert.

Durch die große Zahl an Dialogpartnern entsteht ein Polylog, ein ständiges Spiel unterschiedlichster Perspektiven und Gesichtspunkte, von verschiedenen Orten des Schreibens aus, die zugleich von einer chronologisch verankerten Veränderung gerade auch der sich wandelnden Protagonisten, der Hauptfiguren dieses Briefromans, berichten. Man könnte Montesquieus Briefroman wohl am besten mit einem Mobile vergleichen, in welchem alle Teile in Bewegung sind. Die Chronologie wird dabei nicht nur individuell nach persönlichen Erlebnissen, sondern auch kollektiv und geschichtlich verankert, insoweit etwa der Tod von Louis XIV im September 1715 oder das Exil des Parlaments von 1720 als geschichtliche Orien- 
tierungspunkte in den Text eingeblendet werden. Auf diese Weise ergibt sich die folgende Grundstruktur des gesamten Textes, die wir an dieser Stelle kurz zusammenfassen wollen.

Die Reise der beiden Perser von Isfahan nach Paris umfasst insgesamt dreiundzwanzig Briefe und dauert dreizehneinhalb Monate vom 19. März 1711 bis zum 4. Mai 1712. Auf diesen Teil folgt Paris und die abendländische Welt rund um den Tod des Sonnenkönigs Louis XIV: Die Herrschaft von „Ludwig dem Großen“ umfasst neunundsechzig Briefe und dreieinhalb Jahre von Mai 1712 bis September 1715 mit einem Bruch im zweiundneunzigsten Brief. Darauf folgt die Zeit der Régence mit vierundfünfzig Briefen und insgesamt fünf Jahren von September 1715 bis November 1720 mit einem abschließenden Urteil im hundertsechsundvierzigsten Brief zusammen mit der „conclusion occidentale“ der Persischen Briefe. Das Drama des Serails umfasst insgesamt vierzehn Briefe, wobei die Unordnung oder das Durcheinander im Serail drei Jahre andauert, obwohl dieses Thema seit mehr als einem Jahr vergessen schien. Der Große Eunuch stirbt am 5. Juni 1718 und Solim übernimmt die Macht am 4. Oktober 1719.

Im Kontext dieses kurz zusammengefassten Zeitschemas werden die beiden Welten, Abendland und Morgenland, durch die reisende Gestalt Usbeks und deren Bewegungen miteinander vermittelt - zumindest in der Fiktion. Gerade weil es aber diese Fiktion in vielerlei Hinsicht historiographisch und damit nichtfiktional in sich hat, nimmt sie viele nicht-fiktionale Gattungen wie Abhandlung, Traktat, ja auch den Reisebericht in sich auf, so dass es sich im Grunde um ein schönes Beispiel friktionaler Schreibtechniken handelt. Als friktionales Schreiben bezeichne ich ein Schreiben, das zwischen Fiktion und Diktion ständig hin- und herpendelt. ${ }^{27}$ Vor dieser Hintergrundfolie bilden die Motive von Orient und Okzident jene kontrastive Struktur heraus, in deren Bereich sich die eigentümliche Spannung der Lettres persanes entfaltet.

Wenn insgesamt sechzig Briefe dem Morgenland gelten, so widmen sich einhundert Briefe dem Abendland, so dass sich ein deutliches Übergewicht zugunsten des Okzidents herausbildet. Dominieren dabei zu Beginn die Sittenstudien, so beherrschen gegen Ende die politischen und soziologischen Überlegungen die Szenerie, besonders mit Blick auf das Abendland. Neben Frankreich kommen auch andere europäische Länder ins Blickfeld, doch herrschen mit Ausnahme Englands in diesen Fällen Humor und Satire gegenüber objektiveren und deskriptiven Darstellungsformen vor.

27 Weitere Erläuterungen dieses Begriffs finden sich bereits im vierten Kapitel in Ette, Ottmar: Roland Barthes. Eine intellektuelle Biographie. Frankfurt am Main: Suhrkamp Verlag 1998. 
Damit ist die Diegese des gesamten Briefromans noch nicht ausgeschöpft. Kleinere Ausflüge führen die Leserschaft in andere Regionen der Welt, so etwa mit Blick auf Spanien und Portugal in die überseeische Kolonialgesellschaft in Amerika, die selbstverständlich auch in Montesquieus Lettres persanes nicht fehlen darf. Denn sie ist genuiner Teil des von Europa geprägten und kolonial beanspruchten Raumes. An dieser Stelle möchte ich Ihnen lediglich ein kurzes Beispiel dafür zeigen, wobei Sie ohne Mühe erkennen können, wie sehr Montesquieus Spanienbild den Grundton für das gesamte 18. Jahrhundert vorgab, ein Heterostereotyp Spaniens, das sich noch in dem bereits zitierten Artikel der Encyclopédie méthodique wiederfinden lässt. Im Folgenden also in einem Brief Usbeks ein kurzes Resümee der Kolonialgeschichte von Spaniern und Portugiesen:

Diese beiden Nationen, welche mit einer unbegreiflichen Schnelligkeit unermessliche Königreiche erobert hatten, waren mehr über ihre eigenen Siege erstaunt als die besiegten Völker über ihre Niederlage, und sie sannen auf die Mittel, sie zu erhalten; und so schlugen sie, ein jeder für sich, einen anderen Weg ein.

Die Spanier, verzweifelt darum bemüht, die besiegten Nationen in ihrer Treue zu halten, ergriffen die Partei, diese Völker auszulöschen und aus Spanien treue Völker dorthin zu schicken. Niemals ward ein schrecklicher Plan so genauestens erfüllt. Man sah ein Volk, so zahlreich wie alle Völker Europas, zusammen bei der Ankunft dieser Barbaren von der Erde verschwinden, Barbaren, welche, als sie das westliche Indien entdeckten, allein daran gedacht $\mathrm{zu}$ haben schienen, allen Menschen zu entdecken, was die letzte Periode der Grausamkeit sein würde.

Dank dieser Barbarei behielten sie dieses Land unter ihrer Herrschaft. Beurteile an ihren Wirkungen, wie todbringend sie sind: Denn schließlich war ein so grässliches Hilfsmittel einzigartig. Wie sonst hätten sie so viele Millionen von Menschen im Gehorsam zurückhalten können? ${ }^{28}$

Ich wollte Ihnen anhand dieser Passage zeigen, dass es im 18. Jahrhundert geradezu unmöglich ist, über Amerika zu schweigen, wenn über Europa - in welcher Weise auch immer - gesprochen wird. Wollte man leicht übertreiben, so könnte man formulieren: Amerika als Subjekt ist völlig abwesend, als Objekt aber omnipräsent. Und dies auch dann, wenn die Blickrichtung im Grunde eine andere ist, weil in Montesquieus Briefroman ja das Abendland in einen Bezug mit dem Morgenland gestellt wird.

Die angeführte Passage zeigt uns weiterhin, wie sehr die Spanier als kolonialistische Nation in Europa verhasst waren, obwohl die wichtigsten jener Nationen, die sich am meisten über Spanien beklagten, selbst kolonialistische Aktivitäten entfalteten oder zumindest derartige Hoffnungen hegten. Die Allgegenwart der

28 Montesquieu: Lettres persanes, Bd. 2, S. 71. 
„Leyenda negra“, der „Schwarzen Legende“ um ein blutiges Spanien, prägt das Spanienbild des 18. Jahrhunderts mehr als alles andere. Doch ist die kolonialistische Erfahrung der Europäer so traumatisch, dass die gesamte Schuld gleichsam auf Spanien abgeladen werden muss.

Historisch gesehen steht Usbeks Darstellung also in völliger Übereinstimmung mit den in Europa auf Spanien projizierten Vorwürfen, entspricht aber nicht den geschichtlichen Tatsachen. Es gab in Spanien keinen Plan, die indigene Bevölkerung auszurotten, um die Macht behaupten zu können. Von inselartigen Zentren aus versuchte man vielmehr, die dringend benötigten Arbeitskräfte auf Pflanzungen und in Bergwerken auszubeuten. Der Kolonialismus der zweiten Phase beschleunigter Globalisierung war keineswegs menschenfreundlicher. Denn die Ausbeutung durch die neuen Führungsmächte Holland, Frankreich und England war noch raffinierter und brutaler, wie man am Beispiel von Saint-Domingue und der nachfolgenden Haitianischen Revolution ohne Schwierigkeiten aufzeigen kann.

Sehr verallgemeinernd könnte man festhalten: Der menschenverachtende Kolonialismus Spaniens zielte nicht auf Auslöschung, sondern ging inselhaft vor, während das Vorrücken der britischen Kolonisten flächenhaft war und sich an einer „Frontier“ ${ }^{29}$ in Amerika orientierte. Auf diesem Territorium wurde die indigene Bevölkerung vertrieben oder ausgelöscht, um beim weiteren Vorrücken dieser „Frontier“ wiederum mit Extermination bedroht zu werden. Am Ende dieses Prozesses blieben in der angelsächsischen Kolonisierung nur Reservate kleiner indigener Gruppen, die bis heute entrechtet sind. Machen Sie sich also Ihr eigenes Bild! Doch möchte ich mich an dieser Stelle nicht auf die nutzlose Diskussion einlassen, wer den schlimmeren Kolonialismus, wer die menschenverachtendere Sklaverei zu verantworten hat: Jeder Kolonialismus und jede Sklaverei sind ebenso menschenverachtend wie verachtenswert.

Kommen wir zurück zum Kontrast zwischen Orient und Okzident! Zu beiden Kulturkreisen wurden im Übrigen mehrere Serien von Lektüren als Bezugstexte Montesquieus herausgearbeitet, Forschungsergebnisse, auf die ich mich an dieser Stelle freilich nicht detailliert einlassen kann. Immerhin sei an dieser Stelle zumindest festgehalten, dass Montesquieu ganz entschieden im Sinne der Querelle ein „Moderner“ ist: Nur sehr selten verweist er auf antike Quellen, aktuelle Autoren herrschen bei weitem vor. Freilich muss man auch feststellen, dass der Literatur im Netzwerk von Montesquieus auf die Lettres persanes bezogenen Intertextualität insgesamt eine eher bescheidene Rolle zukommt.

29 Zur Gegenüberstellung dieser beiden Modelle vgl. auch Ette, Ottmar: Von Inseln, Grenzen und Vektoren. Versuch über die fraktale Inselwelt der Karibik. In: Braig, Marianne / Ette, Ottmar / Ingenschay, Dieter / Maihold, Günther (Hg.): Grenzen der Macht - Macht der Grenzen. Lateinamerika im globalen Kontext. Frankfurt am Main: Vervuert Verlag 2005, S. 135-180. 
Wie dem auch immer sein mag: Montesquieus Neigung zu den Modernen kommt schon in einer frühen Passage seiner Lettres persanes zum Vorschein. In ihr wird aus orientalisierender Sicht über die Bemühungen der Querelle des Anciens et des Modernes und über die Gründe dafür nachgesonnen, die Ansichten und den Wert von Männern heißblütig zu diskutieren, die bereits seit über zweitausend Jahren in ihren Gräbern versunken seien. Auch dies ist gewiss eine Möglichkeit, die Querelle zu deuten und Stellung zu beziehen. Für Montesquieu jedenfalls war diese Sache längst entschieden: Die Anhänger der Antike, in einem normativen Sinne wohlgemerkt, waren längst der Lächerlichkeit preisgegeben. Wir sehen dies in aller Deutlichkeit im sechsunddreißigsten Brief seiner Lettres persanes, wo sich Montesquieu aus der Perspektive der Perser des Jahres 1713 über diese Querelle des Anciens et des Modernes lustig macht. Er lässt seine persischen Briefpartner die Köpfe darüber schütteln, worüber sich ernsthafte Franzosen zur damaligen Zeit noch echauffieren oder den Kopf zerbrechen könnten.

Im Übrigen lag auch für Montesquieu die Zukunft nicht nur Europas, sondern der Welt insgesamt nicht mehr im Süden, sondern im Norden. Er bestätigt damit jene Drift Kern-Europas nach Norden, von der ganz zu Anfang unserer Vorlesung Pierre Chaunu gesprochen hatte. Die tatkräftigen und handeltreibenden Völker des Nordens - und allen voran England und Holland - sind die Modelle und Vorbilder, für die der französische Schriftsteller und Philosoph plädiert. Dies macht uns auf eine zusätzliche Dimension des verbreiteten französischen Spanienbildes im Zeitalter der Aufklärung aufmerksam. Denn es begann zu diesem Zeitraum die Abrechnung mit der ersten Phase beschleunigter Globalisierung durch an ihr nicht oder nur wenig beteiligte Nationen, die nun eine zweite Phase beschleunigter Globalisierung auf den Weg brachten. Es ging folglich um eine Art Tilgung der ersten, iberisch geprägten Globalisierung durch eine stärker west- und mitteleuropäisch geprägte Globalisierungsphase, die sich als ,gerechtere‘ präsentierte und in Szene setzte.

Wir wissen heute, dass diese zweite Phase beschleunigter Globalisierung keineswegs zum größeren Nutzen der von den neuen Kolonialmächten nicht besuchten, sondern heimgesuchten Völker führte. Sie musste jedoch auf einer fundamentalen Kritik an jenen Nationen beruhen, von welchen die erste Phase ausgegangen war. Diese aufklärerische Kritik vermochte aber gleichwohl nicht zu verhüllen, dass es erneut Europa als Gesamtheit war, von wo aus diese weltverändernden (und die anderen, nicht-europäischen Völker nicht als eigentliche Subjekte anerkennenden) Bewegungen ausgingen. Es handelte sich folglich um eine durchweg interessegeleitete Kritik, die auf ein Dilemma jeglicher Kritik verweist, sobald sie sich bestimmte Interessen zu eigen macht.

Die Schwerpunkte der Impulssetzung haben sich nicht nur innerhalb Europas verschoben: Die Verlagerung hat auch Folgen für die Globalisierungsweise, 
die nun von Nationen wie England, Frankreich und Holland getragen wird. Eben dies sind die Nationen, welche Montesquieu im Übrigen auch auf seiner Reise besuchen sollte, die er von 1728 bis 1731 durch jene Teile des Alten Kontinents durchführen wird, welche das ,kleine، Europa im Sinne Pierre Chaunus darstellen. Montesquieu wollte aus eigener Erfahrung die Länder kennenlernen, welche zu wesentlichen Impulsgebern der Entwicklung des Kontinents und zum eigentlichen Motor Europas mit Blick auf dessen weltweite Ausweitung wurden. Hatte er in seinen Lettres persanes die Blickwinkel persischer Reisender portraitiert, so versuchte er nun, als Franzose neue Blickwinkel gegenüber führenden Ländern Europas einzunehmen und von diesen Vorbildern auf den verschiedensten Ebenen zu lernen. Man darf sagen, dass ihm dieses Vorhaben, den Kreis seiner Ideen und Vorstellungen durch eigene Reisen zu erweitern, unter Berücksichtigung seiner sich anschließenden Werke mehr als überzeugend gelang.

In Montesquieus Lettres persanes besteht ein aufschlussreiches Phänomen darin, dass der vorgespiegelte Blick von außen, der ja - wie wir wissen - nur ein maskierter, verkleideter Blick eines Franzosen auf Frankreich und eines Europäers auf Europa ist, eine Art der Distanzierung hervorbringt, bei der das Eigene verfremdet und gerade dadurch in seinen Grenzen und in seinem Selbstverständnis kenntlich gemacht wird. Europa entsteht als Vorstellung aus der Distanzierung, so dass immer wieder die grundsätzliche Andersheit des nicht-europäischen, nichtchristlichen, nicht-abendländischen Lebenswissens und Way of Life in den Fokus rückt. Dieses Element, das sich auf allen Ebenen immer wieder durch die Briefe und Überlegungen der verschiedenen Briefpartner zieht, ist folglich von zentraler Bedeutung - eine Tatsache, die auch vor der planetarischen Dimension unseres irdischen Daseins nicht Halt macht.

Gerade für das 18. Jahrhundert und die Aufklärung ist ja diese irdische, planetarische Dimension ein wichtiger Referenzpunkt für philosophische Überlegungen unterschiedlichster Kalibrierung. Sehen wir uns in diesem Zusammenhang das Schreiben des jungen Rica an Usbek an, in dem allgemeine Überlegungen über die Möglichkeiten von Fremd- und Selbsterkenntnis angestellt werden:

Es scheint mir, Usbek, dass wir die Dinge nur durch einen geheimen Rückgriff auf uns selbst beurteilen. Ich bin nicht überrascht, dass die Neger den Teufel in einem strahlenden Weiß ausmalen und ihre eigenen Götter so schwarz wie Kohle; dass die Venus bestimmter Völker Brüste besitzt, die ihr bis zu den Schenkeln herabhängen; und dass schließlich alle Götzendiener ihre Götter mit einer menschlichen Figur versehen und mit all ihren eigenen Neigungen ausstatten. Trefflich hat man gesagt, dass wenn die Dreiecke einen Gott erschüfen, sie ihm alsbald drei Seiten gäben.

Mein lieber Usbek, wenn ich Menschen sehe, die ein Atom erklimmen, das heißt unsere Erde, die ja nur ein Punkt im Universum ist, und sie direkt davon Modelle für die 
Vorsehung abziehen, so weiß ich nicht, wie ich soviel Extravaganz mit soviel Kleingeistigkeit ins Verhältnis setzen soll. ${ }^{30}$

In dieser Briefpassage wird die Relativität aller Vorstellungen des Guten wie des Bösen, des Schönen wie des Hässlichen, des Konkreten wie des Abstrakten herausgestellt. Die textuellen Grundlagen hierfür sind zweifellos die von den Europäern gemachten und in ihren Chroniken und Reiseberichten festgehaltenen Erfahrungen der ersten Phase beschleunigter Globalisierung in der Neuzeit. Die seit Beginn des sogenannten „Descubrimiento“ stattgefundenen Debatten und Diskussionen waren für die Auseinandersetzung mit verschiedensten Formen kultureller Alterität von größter Bedeutung, ${ }^{31}$ so dass der interkulturelle Dialog ohne jeden Zweifel grundsätzliche Einsicht bei einer intellektuellen Elite in die Relativität kultureller Vorstellungen und Konventionen erzeugte.

Dies war eine wichtige Voraussetzung für die Bewältigung der bald schon heraufziehenden Herausforderungen, die sich ab Mitte des 18. Jahrhunderts im Verlauf der zweiten Phase beschleunigter Globalisierung konkretisieren sollten. Die Vorstellungen Montesquieus weisen dabei - wie der nachfolgende sechzigste Brief der Lettres persanes belegen mag - deutlich in Richtung einer Reflexion über kulturelle Differenz vor dem Hintergrund nicht nur der Vertreibung der Juden aus Spanien. Dabei handelt es sich um eine Vertreibung, die Spanien am meisten geschadet habe. Sie generieren darüber hinaus eine Einsicht in die Tatsache, wie sehr die leichte Differenz zwischen zwei christlichen Religionen Frankreich in den Religionskriegen an den Rand des Abgrunds getrieben habe. Montesquieu wandelt hier auf den Spuren seines Landsmannes Montaigne. Denn bei einer historisch etwas distanzierteren Betrachtung und einer klaren Abtrennung des Religiösen vom Politischen wird deutlich erkennbar, wie gering die Unterschiede zwischen beiden Konfessionen doch waren und noch immer sind. Und doch habe man sich wegen derartiger Unterschiede die Köpfe eingeschlagen und erbitterte, selbstmörderische Kriege geführt.

Gleichzeitig wird eine Einsicht in die Tatsache deutlich, dass es gleichsam keine ,unbefleckte Erkenntnis“ gibt, dass also jedes Urteil über andere oder das Andere wie das Eigene vom jeweiligen kulturellen Standpunkt des Urteilenden abhängt. Wir können als Beurteilende nicht von uns und unserem Standpunkt abstrahieren und weisen in unserem Denken stets einen „retour secret“ auf uns selbst auf, nehmen uns sozusagen bei der Einschätzung anderer Kulturen mit, wenn wir andere Sichtweisen und Perspektiven beurteilen oder gar verurteilen.

30 Montesquieu: Lettres persanes, Bd. 1, S. $126 \mathrm{f}$.

31 Vgl. hierzu Todorov, Tzvetan. La conquête de l'Amérique. La question de l'autre. Paris: Seuil 1982. 
Derartige Einsichten müssen nicht in einen absoluten Kulturrelativismus münden, wie dies auch bei Montesquieu durchweg nicht der Fall war, wohl aber in die Überzeugung, dass eine gewisse Distanz zur eigenen Position sehr hilfreich für ein beiderseitiges Zusammenleben ist, wie es etwa im sechzigsten Brief vorgeführt oder zumindest skizziert wird. Im Kern geht es bei diesen Fragen und Herausforderungen - und hier berühren wir einen, ja vielleicht sogar den zentralen Punkt der Lettres persanes - um die Problematik, wie wir in Frieden und Differenz auf diesem Planeten zusammenleben können. Es geht, mit anderen Worten, um menschliche Konvivenz und um ein darauf bezogenes ZusammenLebensWissen. ${ }^{32}$

Darüber hinaus wird in Ricas Worten die Relativität des kleinen Menschleins auf einer so geringfügigen Erdkugel deutlich, welche nur einen kleinen Teil jenes Universums darstellt, das wir stets als ,Universalisten' im Munde führen. Damit klingen Aspekte an, welche der von Montesquieu später angegriffene Voltaire in seinen Contes philosophiques so meisterhaft erkunden wird. In Ricas Überlegungen wird erneut deutlich, wie sehr das Eigene und das Fremde im planetarischen und das heißt auch: im globalen und globalisierten - Maßstabe zu einer punktuellen Einheit verschmelzen, welche sich im Rahmen des Universums als eher marginal ausnehmen. Derartige Vorstellungen, wie sie nicht nur Voltaires Contes philosophiques, sondern die gesamte Aufklärungsepoche prägen, machen einerseits auf die Relativität aller Begriffe und auf ein Streben nach einem Zusammenleben im Zeichen der Toleranz des 18. Jahrhunderts aufmerksam. Andererseits verweisen sie auch auf die jeweilige Abhängigkeit vom raumzeitlichen Kulturkontext der Betrachter und auf die Notwendigkeit, die unterschiedlichsten Sachverhalte in einem globalen Maßstab zu begreifen.

Neben dieser Distanzierung oder Distanznahme, die für Erkenntnis des Eigenen wie des Fremden unersetzlich ist, gibt es noch einen zweiten Aspekt, der für unsere Überlegungen relevant ist, betrifft er doch die mit dem ersten verknüpfte anthropologische oder ethnographische Dimension. Mit diesem wiederum verbunden ist ein weiterer, nicht weniger wichtiger Komplex, den wir als die Ethnologie oder Anthropologie des Eigenen bezeichnen könnten. Es handelt sich um eine Art Geburt des anthropologisch-ethnologischen Blickes, der sich nicht mehr auf das Fremde, sondern auf das Eigene richtet und dieses Eigene als fremd und zugleich doch vertraut, als heimlich und - im Sinne Sigmund Freuds - als unheimlich und beunruhigend zugleich versteht. Beschäftigen wir uns damit etwas näher!

Diese Auto-Anthropologie, dieser von einem französischen Autor mit Hilfe fiktionaler außereuropäischer Reisender auf Frankreich geworfene anthropologi-

32 Vgl. hierzu Ette, Ottmar: ZusammenLebensWissen. List, Last und Lust literarischer Konvivenz im globalen Maßstab (ÜberLebenswissen III). Berlin: Kulturverlag Kadmos 2010. 
sche Blick, wird gerade in den Briefen Usbeks und Ricas aus Paris immer wieder veranschaulicht, man könnte sagen lustvoll ausgekostet. $\mathrm{Zu}$ diesem ganzen für die Lettres persanes zentralen Komplex wären Hunderte von Beispielen zu nennen, wenn etwa die Sitten der Pariser und Pariserinnen in Szene gesetzt werden zu den verschiedensten Anlässen, die das Stadtleben so bieten kann. Wir erleben beispielsweise die Reaktionen der Pariser im Theater und in der Oper, also in kulturellen Institutionen und ,Vorrichtungen', die von den persischen Besuchern in ihrer Intentionalität nicht sogleich durchschaut werden. Vielmehr fällt unseren persischen Besuchern spontan auf, wieviel Pomp sich um die Bühne herum und nicht nur auf ihr - gebildet hat und wie sehr sich die Inszenierungen nicht nur auf den Bühnenraum beschränken.

Andererseits findet sich viel Kritisches über Kleriker und Kirchenleute, ist der Antiklerikalismus doch ein Grundzug zumindest der französischen Aufklärung, so dass spitze Bemerkungen über Klerus und Kirche über den gesamten Briefroman gut verteilt sind. Die Priester werden in den Briefen der Perser zumeist als Derwische bezeichnet; und diese Verfremdung des gewohnten Bildes entkleidet die Männer der Kirche nicht nur der Normalität und Selbstverständlichkeit, sondern gibt ihnen allein vermittels dieses lexikalischen Kunstgriffs einer fremden Benennung einen exotischen, fremdartigen, bisweilen völlig unverständlichen Habitus. Es ist, als könnte man die gewohnten Riten und Handlungsweisen der eigenen Kultur urplötzlich nicht mehr genau nachvollziehen, so sehr werden an derlei Stellen die Konventionen und die Konventionalität der verschiedenen kulturellen und gesellschaftlichen Ebenen sichtbar und durchsichtig gemacht.

Nicht weniger witzig ist die Beschreibung der Académie Française als soziale Körperschaft, in welcher ein gewaltiger Körper mit vierzig Köpfen voller Figuren und Metaphern spricht und denkt und vor allem daher schwadroniert, wobei dieser Korpus mit einem Tribunal verglichen wird, auf dessen Ratschlüsse und Urteile das Volk freilich niemals höre. Wir können nun besser verstehen, warum es gegen die Kandidatur Montesquieus wenige Jahre später doch einige Widerstände gab, trat er doch nun just in jene Reihen ein, die er zuvor in persischer Verkleidung verhohnepiepelt hatte. Dies hatte man dem jungen Autor durchaus übelgenommen - Sie wissen ja, wie Akademiker sind ...

Aus all diesen verschiedenen Facetten, die ich an dieser Stelle natürlich nicht alle aufzählen kann, ergibt sich eine Art Anthropologie europäischer Alltagskultur, die immer wieder aus den unerwartetsten Blickwinkeln vorgeführt wird, so dass sich gleichsam eine Auto-Exotisierung vollzieht, die stets darauf beruht, dass das eigentlich Gemeinte lediglich aus anderer Perspektive verfremdet, gleichsam karnevalisiert wird, ohne aber unkenntlich zu werden. Das Bekannte schimmert immer durch die Verfremdung durch: Der Blick des Anthropologen erweist sich stets als Blick eines Beobachters, der letztlich das Fremde des Eigenen, 
das Fremde in uns selbst beschreibt und in Bewegung setzt. Dabei wird das, was wir als „étranger à nous-mêmes“33 bezeichnen könnten, nicht einfach der Lächerlichkeit preisgegeben, sondern in eine Travestie hineingezogen, welche vielleicht sogar die Essenz, das Wesen der Dinge, durch sich verändernde mobile Blickwinkel freilegt. Denn erst aus verschiedenen Blickwinkeln lässt sich - kubistisch gesprochen - ein Gegenstand in seinem ganzen Umfang begreifen.

Ich möchte Ihnen in diesem Kapitel abschließend gerne einen freilich schmerzlichen Grundzug der beweglichen Positionen Montesquieus in seinen Persischen Briefen aufzeigen, ein Grundzug, der für das 18. Jahrhundert und die Wahrnehmung von (kultureller) Alterität von großer Bedeutung ist. Im sechzigsten Brief haben wir es mit einer Darstellung der Juden zu tun, worauf dann eine Reihe von Überlegungen folgen, die uns auch aus heutiger Sicht sehr zu interessieren vermögen. Sie werden zu Beginn dieses Briefes unschwer feststellen, wie sehr auf Gemeinplätze des in ganz Europa verbreiteten Antisemitismus zurückgegriffen wird. Eine negative Sichtweise der Juden findet sich ebenso in anderen Briefen unserer persischen Freunde, doch verbergen sich dahinter letztlich französische Antisemitismen, also Fragmente eines europäischen Antisemitismus, der bis heute nicht überwunden scheint, sondern sein hässliches Antlitz immer wieder manchmal offen, manchmal verborgen zeigt. Antisemitismus und Rassismus sind offenkundig nicht ein für alle Mal auszurotten, sondern müssen immer wieder von Neuem rational angegangen werden.

Im Bewusstsein dieser unabschließbaren Aufgabe möchte ich Ihnen die beiden Seiten dieser Auffassung, Antisemitismus der versteckten Art und Plädoyer für die Toleranz der expliziten Art, anhand von Anfang und Ende des sechzigsten Briefes der Lettres persanes vorführen. In diesem Zusammenhang sei nicht vergessen, dass - wie schon Hannah Arendt kritisch feststellte - die französischen Aufklärer mit einer ehrenvollen Ausnahme, jener von Denis Diderot, allesamt vom Antisemitismus mehr oder minder stark angefressen waren. So schreibt denn Usbek an Ibben in Smyrna folgende Sätze:

Du fragst mich, ob es Juden in Frankreich gibt? So wisse denn, dass es überall, wo es Geld gibt, auch Juden gibt. Du fragst mich, was sie hier tun? Genau das, was sie in Persien tun: Nichts ähnelt mehr einem Juden aus Asien als ein europäischer Jude.

Sie zeigen bei den Christen ganz wie bei uns eine unbesiegbare Beharrung auf ihrer Religion, die bis zum Wahnsinn reicht.

Die jüdische Religion ist ein alter Stamm, der zwei Zweige hervorbrachte, welche die gesamte Erde bedeckt haben: Ich will sagen den Glauben an Mohammed und den an Christus; oder vielmehr handelt es sich um eine Mutter, die zwei Töchter hervorbrachte, welche

33 Vgl. hierzu Kristeva, Julia: Etrangers à nous-mêmes. Paris: Librairie Arthème Fayard 1988. 
einander mit tausenderlei Wunden versahen: Denn in Sachen Religion sind die sich nächsten einander die größten Feinde. [...]

Es gab in Europa niemals eine Ruhe, die mit jener vergleichbar wäre, welcher sie sich jetzt erfreuen. Unter den Christen beginnt man, sich von jenem Geiste der Intoleranz freizumachen, der sie einst beseelte. Für Spanien hatte es schlechte Folgen, dass man sie verjagte, und auch für Frankreich, wo man die Christen erschöpfte, weil ihr Glaube nur ein wenig von dem ihres Fürsten abwich. Man hat bemerkt, dass der Eifer für die Fortschritte der Religion von der Bindung verschieden ist, die man für sie besitzen muss, und dass es, um sie zu lieben und ihr zu folgen, nicht notwendig ist, jene $\mathrm{zu}$ hassen und $\mathrm{zu}$ verfolgen, welche sie nicht befolgen.

Es wäre zu wünschen, dass unsere Muslime ebenso vernünftig über diesen Artikel dächten wie die Christen; dass man zu guter Letzt Frieden zwischen Hali und Abubeker machen und Gott die Sorge für die Entscheidung überlassen könnte, welche Meriten diese heiligen Propheten jeweils hätten. Ich wünschte, dass man sie mit Handlungen der Verehrung und der Achtung ehrte und nicht mit eitlen Präferenzen; und dass man ihre Gunst verdienen wollte, welchen Platz Gott ihnen auch immer angewiesen haben mag, sei es zu seiner Rechten oder unter den Stufen zu seinem Throne. ${ }^{34}$

In dieser Passage werden die Juden gleichsam als transnationales Volk dargestellt, dessen Einheit und Einigkeit - unabhängig davon, ob es sich um Juden in Asien oder in Europa handelt - auf Grund der beobachtbaren „obstination“ für die jüdische Religion nicht in Frage gestellt wird. Überall, in den verschiedensten staatlichen und kulturellen Kontexten, ist die Religion das entscheidende Moment ihrer inneren Zusammengehörigkeit. Zugleich ist auf wirtschaftlicher Ebene der Hang zum Geld das äußere Zeichen, das den Juden überall, ob in Persien oder in Frankreich, von Christen wie Muslimen als Erkennungsmerkmal angehängt wird.

Von zentraler Bedeutung in dieser Briefpassage ist das entschiedene Plädoyer für eine Toleranz, die sich aus der geschichtlichen Erfahrung verschiedener Länder speist. Denn zum einen markiert das Jahr 1492 nicht nur die sogenannte ,Entdeckung' Amerikas durch Kolumbus und damit den Beginn der ersten Phase beschleunigter Globalisierung, sondern auch die Vertreibung der Juden aus Spanien, eine Vertreibung, die - wie mehrfach in den Lettres persanes deutlich gemacht wird - Spanien selbst am meisten geschadet habe. Ähnlich negativ waren auch die Folgen für Frankreich, das durch seine bürgerkriegsähnlichen Religionsfehden bekanntlich an den Rand des Abgrunds geführt wurde, nun aber - so gibt es der persische Beobachter zu verstehen - aus diesen Fehlern gelernt habe. Denn religiöse Intoleranz und Fanatismus wirkten sich stets negativ auf das wirtschaftliche Wohlbefinden eines Landes aus.

Doch es gibt Gründe, hoffnungsvoll in die Zukunft zu blicken. Denn es scheinen neue Zeiten größerer Offenheit angebrochen zu sein ... so wird Frankreich zu-

34 Montesquieu: Lettres persanes, Bd. 1, S. $127 \mathrm{f}$. 
mindest aus persischem Munde bestätigt. Und die wechselseitige Toleranz, die sich in religiösen Dingen einzupendeln begonnen habe, nutze nicht allein den Juden, die relativ unbehelligt geblieben seien und noch niemals zuvor eine größere Ruhe genossen hätten, sondern vor allem den Christen und damit dem Gros der Bevölkerung. Intoleranz erscheint hier als ein Übel aus anderen Zeiten, das man in Europa immer mehr hinter sich lasse. Ein optimistischer Grundzug durchweht diese Passagen - und die Hoffnung, dass die Zugehörigkeit zu Religionen künftig nicht mehr Quelle von Auseinandersetzungen in der Gesellschaft sein werde.

Ist dieses wichtige Schreiben aus Montesquieus Briefroman auch auf die spezifisch religiöse Dimension toleranten oder intoleranten Verhaltens gemünzt, so wird doch deutlich, dass daraus Rückschlüsse auf die Gesellschaft im Allgemeinen und die Beziehungen verschiedener Kulturen untereinander im Besonderen gezogen werden können. An eben dieser Stelle, so scheint mir, liegt ein ausschlaggebender Teil des Fundaments der Lettres persanes von Montesquieu. Dieses bietet nicht nur die Distanz, welche selbst- und Fremderfahrung erst ermöglicht, und jenen ethnologisch-anthropologischen Blick, der die eigene Alltags-Kultur überhaupt erst kritisch ins Bewusstsein hebt und die historische und kulturelle Bedingtheit und Konventionalität aller Handlungsweisen unterstreicht. Es beinhaltet auch einen neuen Geist in der Erfassung der unterschiedlichen Welten, die auf dieser einen Erde angesiedelt sind, und schließt die Einsicht in die Notwendigkeit mit ein, zwischen diesen Kulturen zu vermitteln, um eine Zeit friedlichen Zusammenlebens in Differenz zu eröffnen.

Usbek und Rica erscheinen als derartige Vermittler, auch wenn sie von Europäers Gnaden handelnde Romanfiguren sind. Zu keinem Zeitpunkt werden sie und dies ist fürwahr entscheidend - als Angehörige einer unterlegenen und negativ gebrandmarkten Kultur dargestellt, sondern als Menschen, die in einer anderen Kultur aufgewachsen sind, deren Alterität sich nur noch spaßeshalber mit Voltaire der Frage aussetzen muss: „Comment peut-on être persan?“ Wie um Gottes Willen kann man ein Perser sein? In den Lettres persanes zeigen sich signifikante Entwicklungen hin zu einer offeneren Weltgesellschaft, auch wenn die grundsätzliche Asymmetrie zwischen den Kulturen keineswegs verschwunden ist. Doch eine friedvolle Konvivenz zwischen unterschiedlichsten Völkern und Kulturen scheint auf unserem Planeten nunmehr möglich. Das 18. Jahrhundert sollte zweifellos ein spannender, aber auch gefährlicher Experimentierraum für ein derartiges Zusammenleben im globalen Maßstab werden. 